\title{
Strike-slip deformations in the West Siberian Basin and their impact on exploration and development of oil and gas reservoirs
}

\author{
Georgy Nikolaevich Gogonenkov, \\ Ahmet Issakovich Timurziev \\ Central Geophysical Expedition JSC, Moscow
}

\begin{abstract}
Extensive 3D seismic exploration has revealed in much of the West Siberian petroliferous basin area a special type of faults and deformations within the sedimentary cover, caused by low-separation basement strike-slip faults. A geologic phenomenon associated with strike-slip fault structures is something new to the understanding of the subsurface structure of West Siberia. Complex morphology, intense disjunctive faulting, block arrangement and enormously wide stratigraphic range of oil and gas presence are characteristic of numerous hydrocarbon fields within the zones of strike-slip fault structures. It would certainly be a risky endeavor to design field development-andproduction projects, drill production wells and conduct geotechnical surveys without confident geomechanical and kinematic models for structure-forming, fluid-conductive and sealing dislocations caused by strike-slip faults in the basement.
\end{abstract}

\section{Introduction}

The West Siberian sedimentary basin is one of the world's largest oil and gasbearing basins with hydrocarbon fields unique in size and volume. Recent decades have seen hundreds of thousands of seismic line-kilometers shot, about 200,000 wells drilled, hundreds of oil and gas fields discovered, and several billion tons of oil and several trillion cubic meters of gas produced. The principal producing zone, the 2,000 to 4,000 m-thick Jurassic and Cretaceous clastic sequence overlain by the Tertiary and Quaternary overburden, is already well studied. However, 3D seismic surveys, subsequent quality processing and detailed interpretation of the acquired data have allowed discovery of essentially

Addresses: G. N. Gogonenkov, A. I. Timurziev: 38/3 Narodnogo Opolcheniya St., 123298 Moscow, Russia, e-mail: gogo@cge.ru

Received: May 13, 2010; accepted: September 27, 2010 
new details in the basin structure complementing the regional tectonic development history and substantially updating geologic models for a good number of large fields. First evidence for the new type of tectonic dislocations in the West Siberian sedimentary basin was reported in publications by Elmanovich et al. (1998), Belyakov et al. (2002) and Gogonenkov et al. (2002). The authors showed the presence of low-magnitude strike-slip systems in the basement that caused complex dislocations in much of the West Siberian sedimentary basin, the dislocations being basically chains of en-echelon faults. Vyssotski et al. (2006) note wide-scale development of these dislocations, without giving, however, any quantitative estimates of this phenomenon. Nor do their publications provide valid information as to what role these strike-slip dislocations play in the formation and in the specificities of numerous oil and gas fields. In this article we prove the presence and delineate the postulated areal extent of an extraordinarily young (Neogene-Quaternary) strike-slip fault system in the West Siberian Paleozoic basement. This system has triggered off complex plicate and disjunctive deformations in the sedimentary cover, which are referred to hereafter as strike-slip fault structures (SSFS). We highlight impacts of SSFS on the tectonic framework and distribution of oil and gas over the study area, and recommend measures to be taken in prospecting, exploration, development and production of such oil and gas fields.

\section{Evidence for the presence of SSFS}

Central Geophysical Expedition, the employer of the authors of this article, processed and interpreted during the 1997-2008 time period a number of 3D seismic surveys shot in central West Siberia within the area shown with a rectangle in the map (Fig. 1). In some of the survey areas, geologically complex tectonic deformations were unraveled in the Jurassic-Cretaceous sedimentary section. Such a typical deformation has been identified in the North Komsomol area, with a large oil-gas-condensate field of the same name. Figure 2 shows a series of dip maps of seismic horizons correlated on 3D data from top Paleozoic basement (horizon $\mathrm{A}, \mathrm{t}=2.7 \mathrm{~s}$, at a depth of about 4,000 m) through a number of distinctly traceable boundaries to horizon $\mathrm{C}, \mathrm{t}=0.9 \mathrm{~s}$, associated with top Cretaceous, at a depth of about $800 \mathrm{~m}$. Note that the 3D survey covers much of the area, exceeding $600 \mathrm{sq}$. $\mathrm{km}$. At the top basement level, a linear suture, about $25 \mathrm{~km}$ long, is seen along the northwestern limit of the survey area. Extending upward for about $1,000 \mathrm{~m}$ to key seismic horizon B (top Jurassic) $(\mathrm{t}=2.25 \mathrm{~s})$, this tectonic phenomenon is quite clearly manifested as an intense deformation zone, up to $1.5 \mathrm{~km}$ wide, feathered by faintly visible shear fractures at an angle of about 45 to the principal dislocation. Upsection toward upper portions of the Cretaceous, the deep NE-striking suture can no longer be discerned on the dip maps; whereas a system of east-west en-echelon faults is clearly seen right above the deep suture. Note that the faults are shaped in helical fashion, changing their 


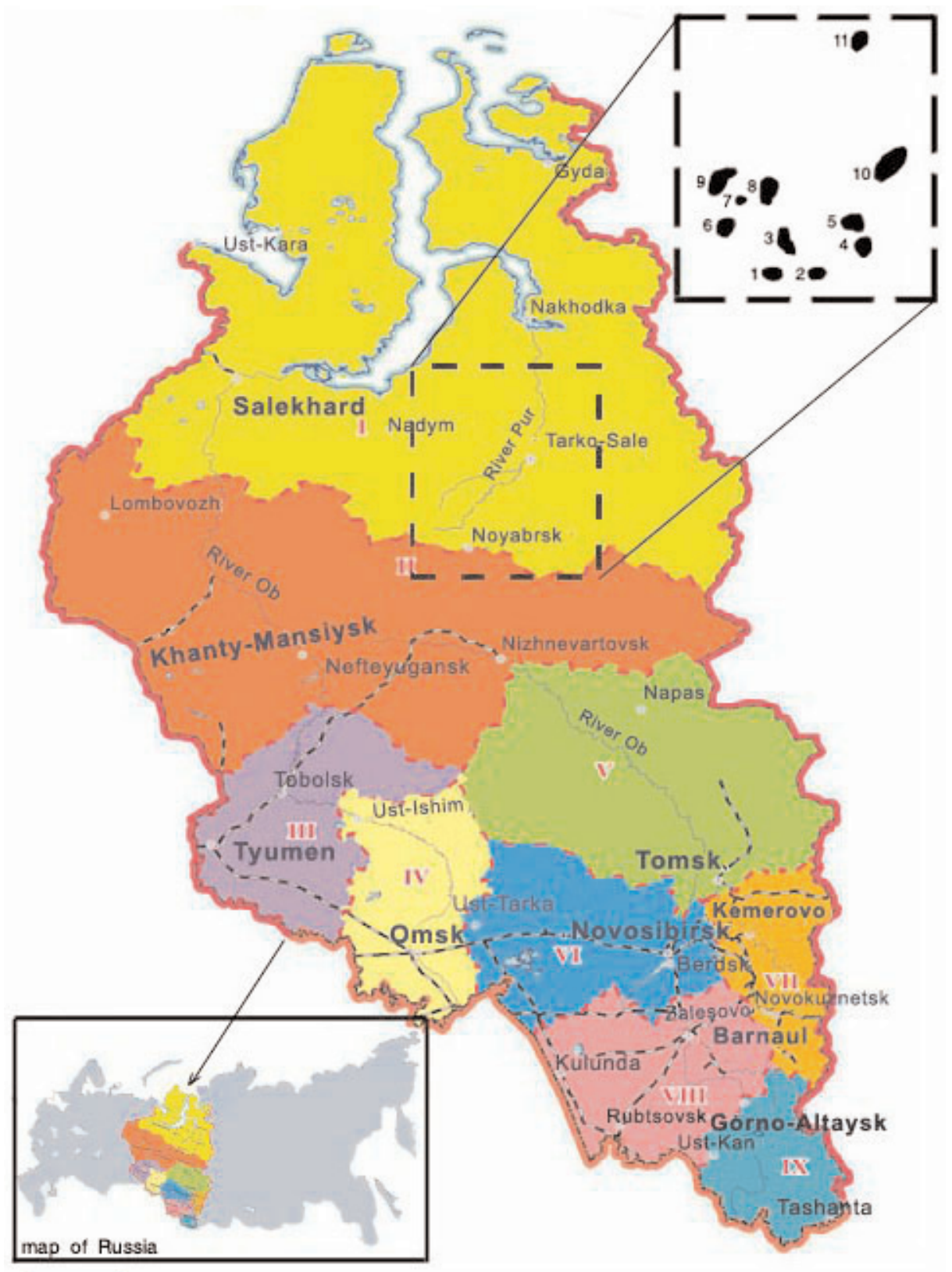

Fig. 1

Map of West Siberia. Dotted rectangle shows area of interest of this article.

Dashed box in the upper right corner shows locations of the fields mentioned in this article: 1. Novogodneye, 2. Yarainer, 3. Yety-Pur, 4. Kharampur, 5. North Kharampur, 6. Komsomol, 7. Metelnoye, 8. Gubkin, 9. North Komsomol, 10. Chasel, 11. Russkoye 


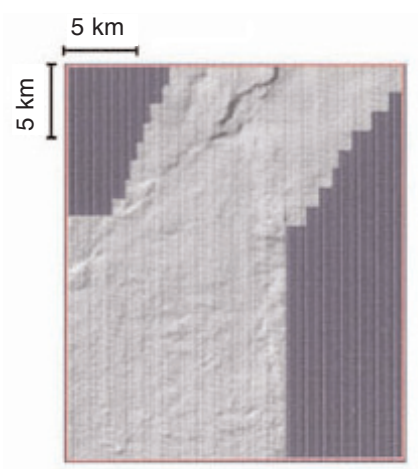

Horizon A

$t \sim 2.70$ s

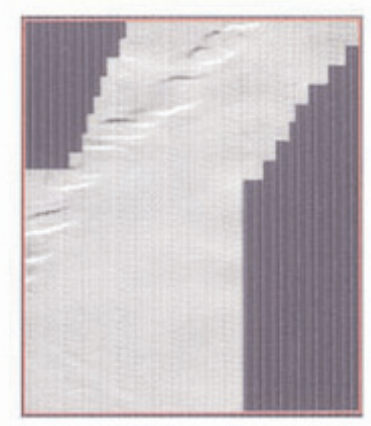

Horizon PK18

$t \sim 1.55 \mathrm{~s}$

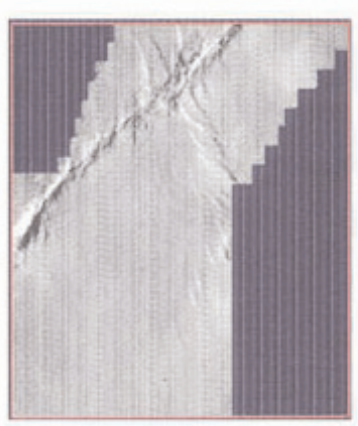

Horizon B

$\mathrm{t} \sim 2.25 \mathrm{~s}$

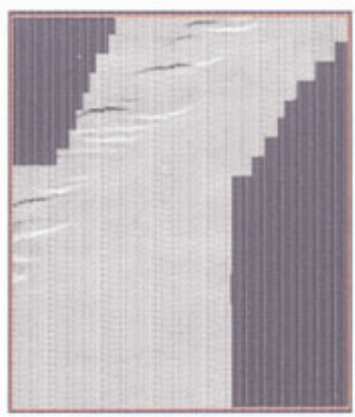

Horizon PK1

$t \sim 1.05 \mathrm{~s}$

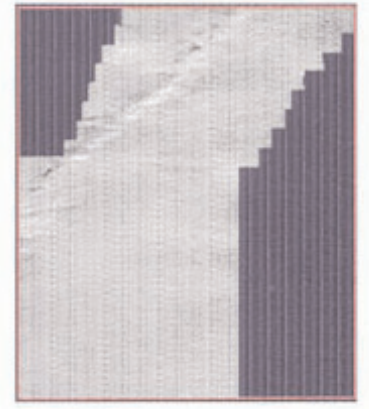

Horizon BP4

$t \sim 2.0 \mathrm{~s}$

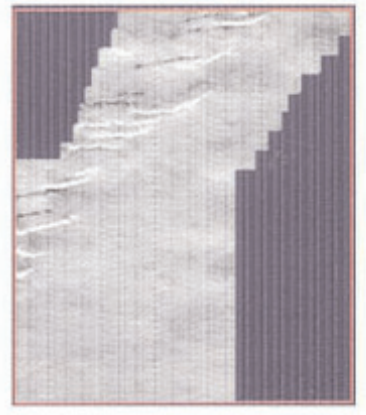

Horizon C1

$\mathrm{t} \sim 0.90 \mathrm{~s}$

Fig. 2

Dip maps of 6 North Komsomol area seismic horizons from top Paleozoic basement (Horizon A) to base Tertiary (Horizon C1). The linear (strike-slip) form on Horizon A is seen higher up to turn into a system of en-echelon faults

vertical displacement direction to the opposite one along the en-echelon. This is manifested in the illumination sign change: with the given illumination direction the echelons at either side of the displacement axis are colored white and black. Vertical cross-sections from a seismic data cube, being perpendicular to the direction of en-echelon faults, make dislocations at different depths visible and allow the magnitude of those dislocations to be assessed. Figure 3 shows two of such vertical cross-sections and their projections to dip maps (shown in Fig. 2) for horizons PK1 (top Cenomanian) and B (top Jurassic). As seen in Fig. 2, the enechelon faults, identified at different stratigraphic levels, make up a single system of nearly vertical faults converging toward the principal basement fault. Some of the faults are continuously detectable from the basement to as far up as almost the Quaternary. Other faults originate and terminate within the sedimentary 

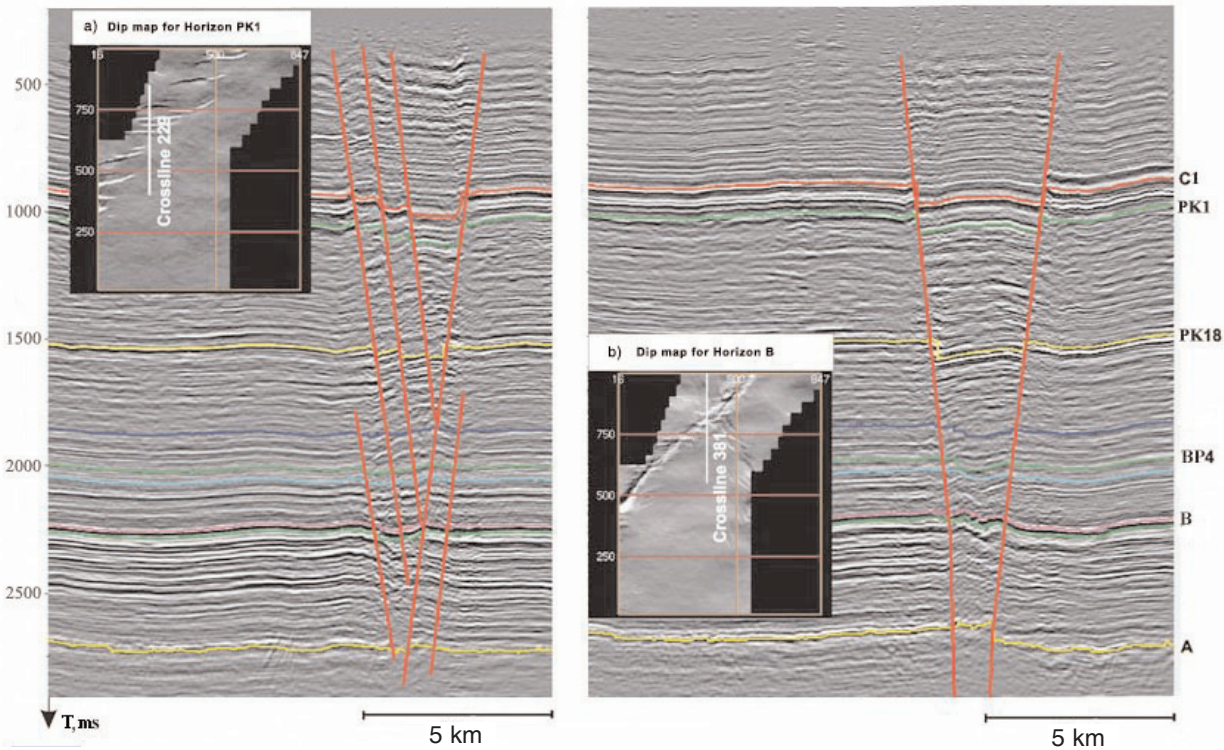

Fig. 3

Seismic sections through the zone of tectonic dislocations in Fig. 2. Boxes show section positions on dip maps along Horizon PK1 (top Cenomanian) (left) and Horizon B (top Jurassic) (right)

cover, but their relationship with the former faults is beyond doubt. The magnitudes and polarity of faults change with depth. Maximal vertical fault throws $(50 \mathrm{~m})$ on the cross-sections are associated with the upper part of the Cretaceous - the Cenomanian.

Once again one should observe the dips at the Bazhenov horizon on the dip map (Fig. 2B). Here, in addition to the major system of en-echelon faults, discussed above, a second system of en-echelon faults is identified. Its axis is almost perpendicular to the axis of the major system of en-echelon faults. Displacement magnitudes in the second system of en-echelon faults are much smaller than those in the major one - just a few meters. Therefore the second system is faintly visible on reflections coming from horizons above and below.

A clear view of en-echelon faults is seen on a series of dip maps constructed from the Gubkin area 3D survey data (Elmanovich et al. 1998) (Fig. 4). The main system of faults runs almost across the very center of the area. Unlike the earlier example, it is practically unidentifiable at basement level (horizon A) because of a multitude of other heterogeneities. But not much higher up, at the Bazhenov horizon (and the closely underlying productive horizon J1), the main system of en-echelon faults is very distinct. It can be seen that the tectonic stresses in the sedimentary cover that were responsible for the emergence of en-echelon faults also led to deformation of reflectors and to the formation of depressions and ridges that are gradually smoothed upward in the section. The reflector is almost 


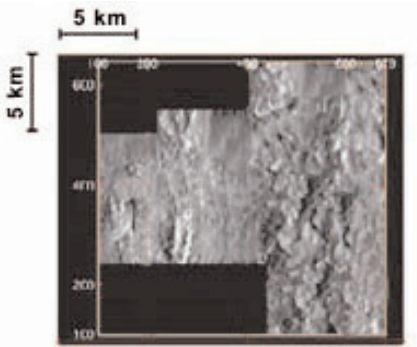

Horizon A

$t \sim 2.74 \mathrm{~s}$

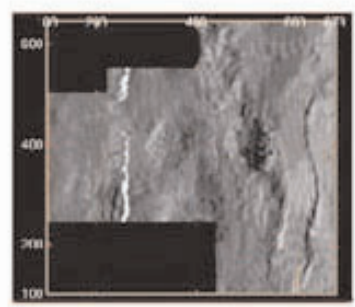

Horizon Ach1

$t \sim 1.85 \mathrm{~s}$

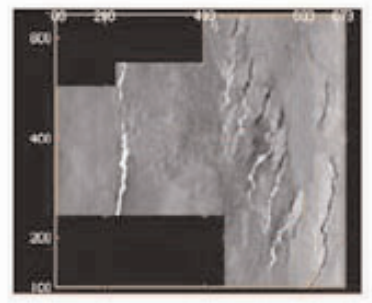

Horizon BP5

$\mathrm{t} \sim 1.73$

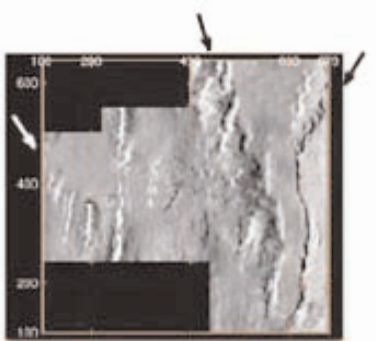

Horizon J1

$t \sim 2.26 s$

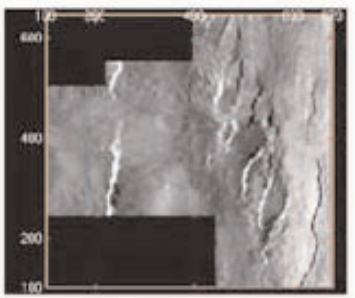

Horizon BP9

$\mathrm{t} \sim 1.80 \mathrm{~s}$

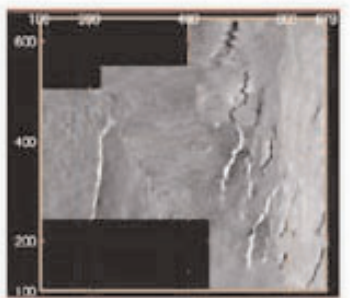

Horizon PK 18

$\mathrm{t} \sim 1.32$

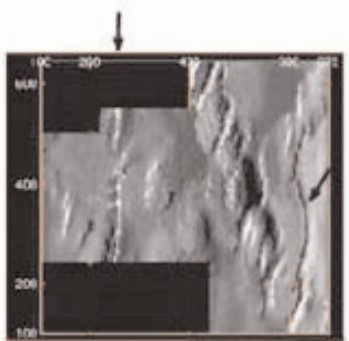

Horizon B

$\mathrm{t} \sim 2.19 \mathrm{~s}$

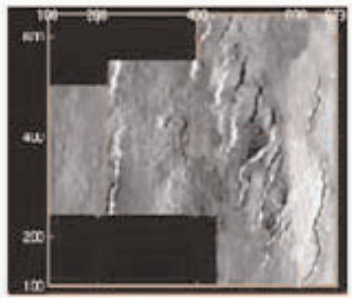

Horizon BP7

$t \sim 1.75$

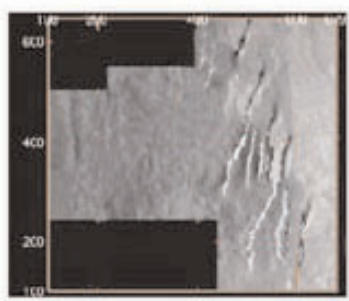

Horizon PK1

$t \sim 0.73$

Fig. 4

Dip maps of key reflectors in the Gubkin area demonstrate a system of complex tectonic dislocations. Arrows on dip map for Horizon J1 point to axes of en-echelon fault systems. Arrows on dip map for Horizon B (top Jurassic) point to "ordinary" faults accompanying en-echelon fault systems

undeformed close to the top Cenomanian (horizon PK1 (top Cenomanian)), although the system of en-echelon faults itself is still distinctly pronounced. In the North Komsomol area, similar to the preceding case, the number and extent of faults change upward in the section. The faults have a complex form; some of them change polarity (direction of throw) along the strike.

Examining further the dips of the Bazhenov horizon on the dip map of the Gubkin area (Fig. 4), another two, less pronounced systems of en-echelon faults 
can be observed. One runs along the western margin of the survey area, practically parallel to the main system. The other is almost perpendicular to the former two systems and starts at the northeastern corner of the survey area. These two systems are well seen on the dip map of the J1 horizon, but no traces of them are observed above the Bazhenov horizon. Note also that two "ordinary" tectonic faults are identified in this area. One of them, with its tilted hanging wall crosses the area in north-south direction at a distance of $5 \mathrm{~km}$ at the basement horizon (Horizon A) and at a distance of $3 \mathrm{~km}$ at the PK1 horizon (top Cenomanian) from the western boundary of the survey area. The other tectonic fault runs close to the eastern boundary of the survey area. It is obviously related to the two systems of en-echelon faults described above and remains within their boundaries.

The most comprehensive description and explanation of the en-echelon fault systems and the related tectonic dislocations is found in W. Jaroszewski's monograph (Jaroszewski 1974). It presents the results of physical modeling of strike-slip dislocations in an elasto-plastic sedimentary cover overlying a relatively rigid basement. The modeling was carried out by M. Gzovsky and E. Chartkova in the Tectono-Physics Lab of the Earth Physics Institute, USSR Ac. of Sc. Figure 5 is a copy of a figure from W. Jaroszewski's monograph showing various development phases of a strike-slip fault from its origination to completion. At the very initiation of the strike-slip fault a series of synclinal and anticlinal drag folds (Fig. 5a) are formed within the sedimentary cover, oriented in an en-echelon manner in relation to the strike-slip axis, above and along a basement fault. The fold reliefs will be seen growing, as the strike-slip dislocation grows, while dip angles of the fold axes will diminish in relation to the dynamicpair vectors. This is the first - plication - phase of a strike-slip origination and development.

Then, as the strike-slip displacement progresses, the tensile force exceeds the rock strength and vertically oriented en-echelon systems of ruptures and the first system of shear fractures begin to occur in the sedimentary cover. Rupture axes are positioned perpendicular to the drag fold axes, while shear fractures are formed in parallel to the drag fold axes (Fig. 5b). Any further strike slip fault growth leads to steeper angles of shear fracture axes, while ruptures open up even more (Fig. 5c). At the same time, a second system of shear fractures occurs in parallel to the principal basement strike-slip fault axis. While the strike-slip fault continues to develop, the second system of shear fractures degenerates into a single fault, thus completing the strike-slip development in the sedimentary cover (Fig. 5 d).

A comparison of the seismically-unraveled system of en-echelon faults and the results of the physical modeling indicates that they are completely analogous. Tectonic dislocations, deformations and en-echelon faults identified in the sedimentary cover are products of incipient (low-magnitude) strike-slip faults within the underlying consolidated basement. Re-examining the North 
a

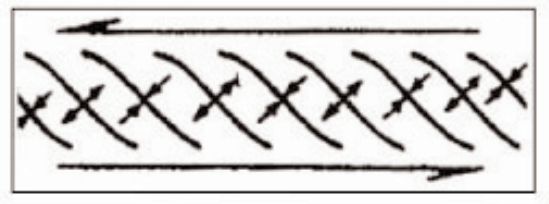

b
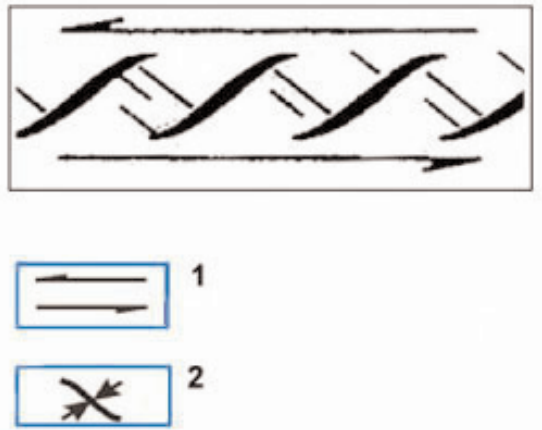

c

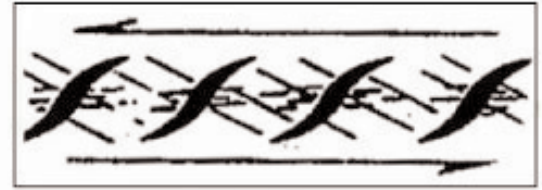

d

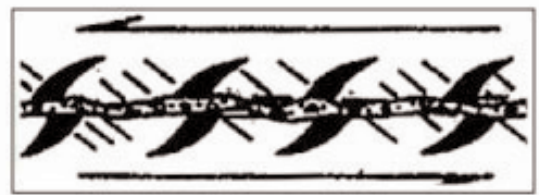

3

4

Fig. 5

Physical models (Jaroszewski 1974) of the 4 faulting phases in the sedimentary cover from the start to the completion of a process triggered off by strike-slip faults in the underlying rigid basement rocks. 1. Dynamic pair of strike-slip fault stresses, 2. Formation of drag folds, 3. En-echelon faults (detachments), 4. Shear fractures: a. Early phase of sedimentary cover dislocation, b. Formation of vertical faults (detachments), c. Formation of shear fracture system along principal axis of strike-slip fault along the basement, $\mathrm{d}$. Complete fault and strike-slip fault along principal basement strike-slip fault

Komsomol area dip maps (Fig. 2) and with the results of the physical modeling in mind, we may say that the strike-slip fault ended the initial phase of its development within the lower part of the sedimentary cover, i.e. between the basement and the Bazhenov horizon. Here, en-echelon faults appear to be a single fault. No traces of the strike-slip fault are seen above Horizon B (top Jurassic). En-echelon faults are extension faults and as such are undoubtedly perfect conduits for vertical migration of fluids. From the results of the physical modeling shear fractures should also be expected to be present parallel to the principal fault axis to serve as channels of hydraulic communication between individual en-echelon faults.

By the time of writing this article, SSFS structures have been identified with confidence in over 20 areas explored with 3D seismic surveys. Figure 6 shows a few more of them. Fault geometries and parameters are different in different areas, but overall they confirm the situation described above. Apart from the features manifested in the above examples, there area other, more complex deformations identified in some other areas of the study territory. These are when and where strike-slip faults are accompanied by lateral compression or 


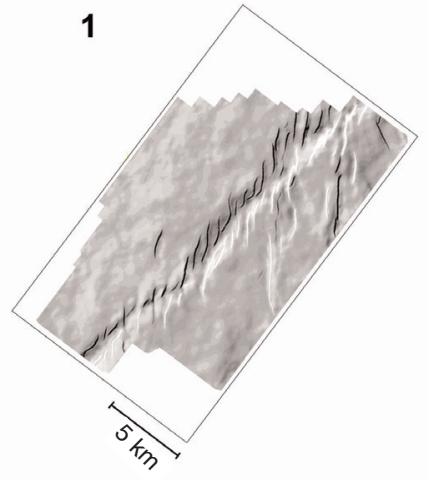

4

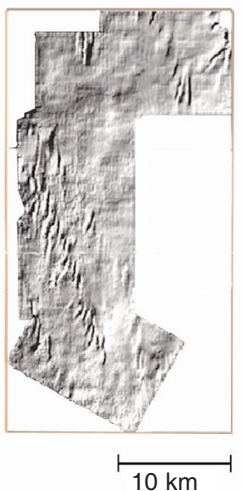

5
2
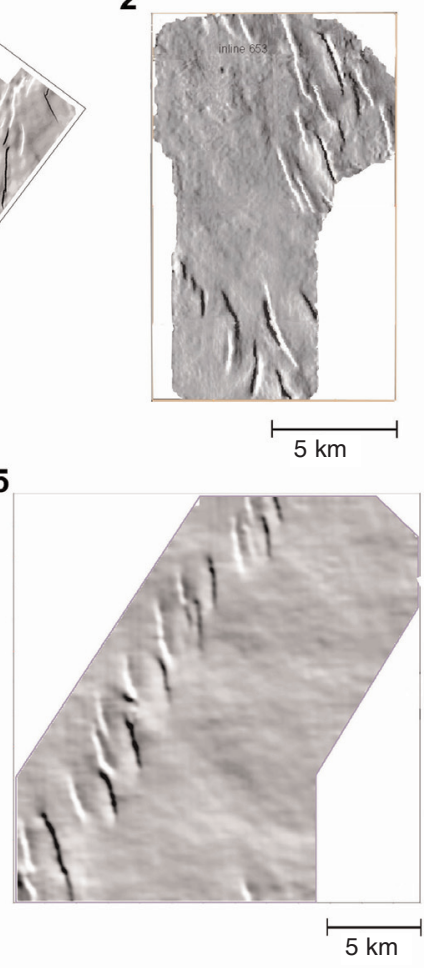

3
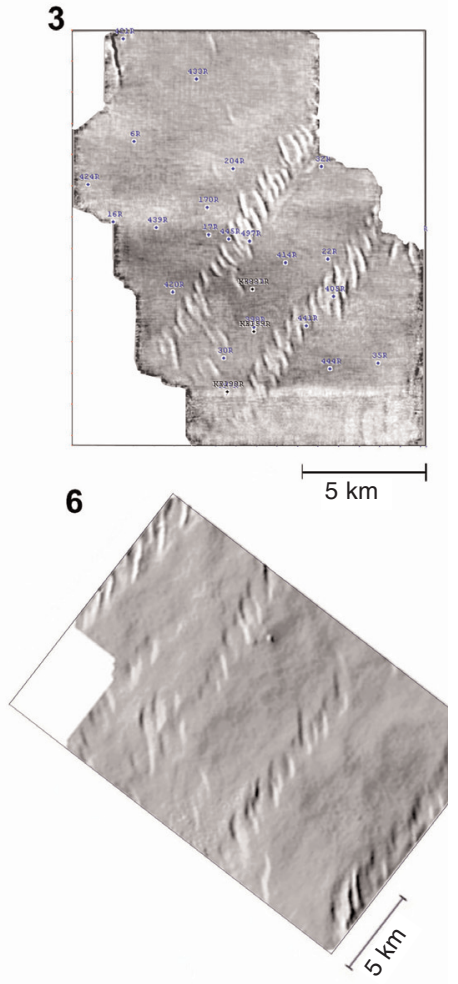

Fig. 6

Basement-strike-slip-generated dislocations in key horizons of the sedimentary cover as identified by dip maps in a number of exploration areas: 1. Metelnaya area, 2. North Kharampur area, 3. Komsomol area, western dome, 4. Kharampur area, 5. Chasel area, 6. Yarainer area

extension. In these instances swell or down-bend of horizons can accordingly be seen in the deformation zones of the sedimentary cover. Examples of such deformations will be shown below. In addition, en-echelon faults are obviously asymmetric: one fault side is broken up much more severely. This can be explained by a more complex configuration of the fault in the basement section when, in addition to the strike-slip, the fault also has a vertical component. This combination of horizontal and vertical basement movements is the cause and explanation for the emergence of nearly vertical feathering (pinnate) normal faults of the type demonstrated in Fig. 4.

\section{SSFS manifestation on $2 D$ seismic data}

How do en-echelon fault systems manifest themselves on the data of 2D seismic surveys that have covered tens of thousands of square kilometers in West 
Siberia? We have analyzed several 2D survey areas that adjoin and overlap 3D survey areas described above and where systems of en-echelon dislocations have been identified. It turns out that even with a sufficiently dense grid of $2 \mathrm{D}$ lines $(2 \times 2 \mathrm{~km})$ the acquired seismic data do not enable the identification of en-echelon faults. The seismic interpreters traditionally find no better solution to represent a dislocated zone than to draw a series of closely positioned parallel faults along the principal basement fault axis. Thus, Fig. 7a shows tectonic faults on the northern dome of the Yety-Pur area brought out with a 2D seismic survey, while Fig. $7 \mathrm{~b}$ on the right is the same map of Fig. 7a with $3 \mathrm{D}$ seismic data inserted. Visual comparison indicates that $2 \mathrm{D}$ data with conventional coverage density are unable to image the real tectonics of the subsurface realm. Thus we may now say with much confidence that the system of parallel faults in the right-hand part of the area of interest is an SSFS zone, but an incorrectly interpreted one.

Similar sub-parallel systems of linear faults can be seen in numerous 2D survey areas of the West Siberian territory studied (Fig. 1). A number of these 2D survey areas adjoin 3D survey blocks. We may postulate with confidence that, as in the

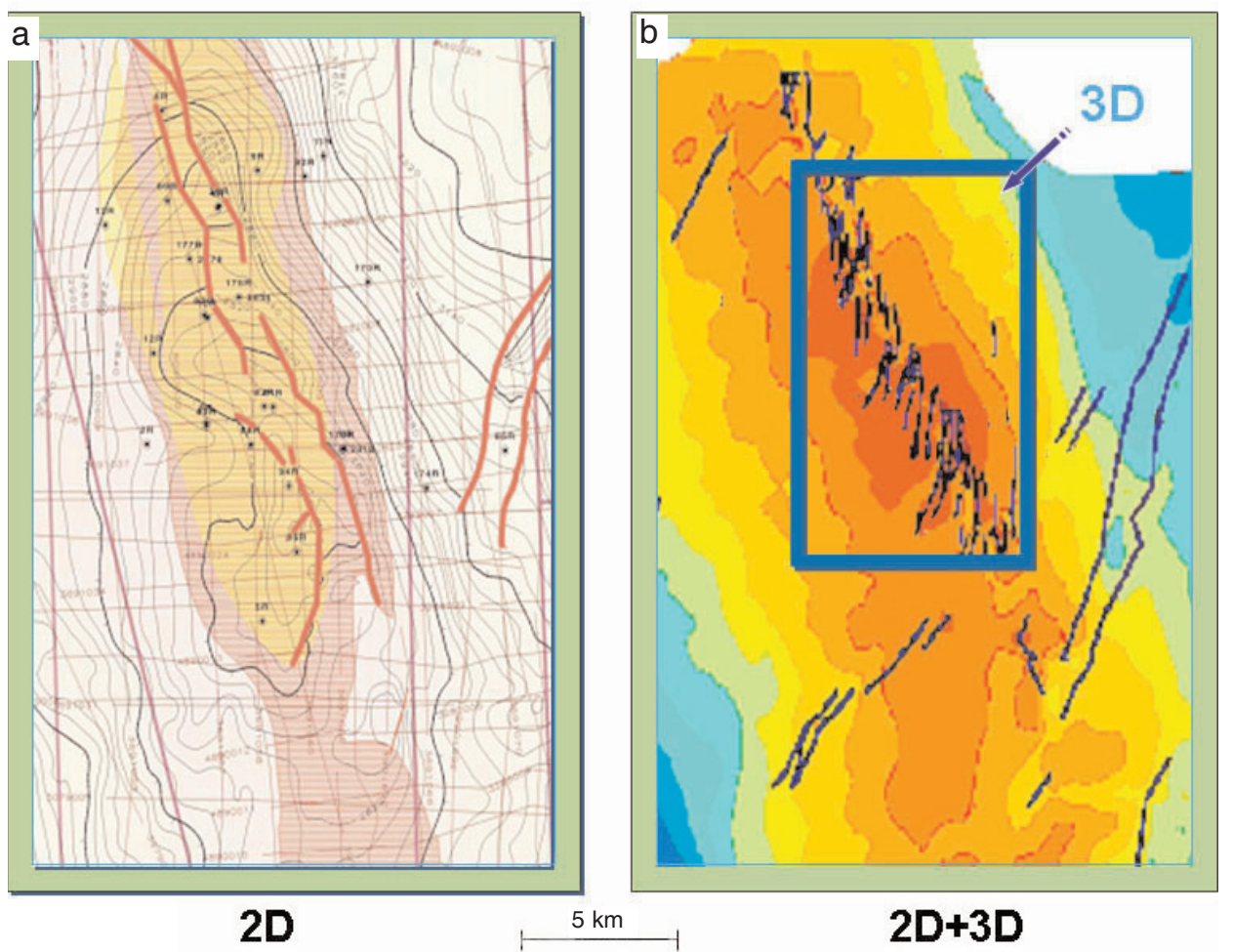

Fig. 7

A comparison of the tectonic interpretations of the Yety-Pur area based on 2D. a) Linear sub - parallel faults) and 3D surveys, b): a multitude of en-echelon faults 
case of the Yety-Pur area, these sub-parallel systems, identified by 2D surveys, are also in reality en-echelon fault systems.

The SSFS studied in the West Siberian territory are of low relief and their polarity changes along the strike. Consequently there are en-echelon localities where no vertical or horizontal displacement is observed. Besides, 3D migration cannot be applied to $2 \mathrm{D}$ seismic data during the processing, while 2D migration along a profile would not be able to recover the true image of the complex faulting system. Misinterpretation of tectonic dislocations seen on 2D data leads to an incorrect structural imaging of target horizons, which in turn would result in a non-optimal siting for prospecting, exploration and production wells. So it can be stated that 2D seismic data may not provide an adequate basis on which to carry out drilling programs in the areas with SSFS.

\section{SSFS development geography}

Figure 8 shows the proved distribution area of strike-slip faults in the Paleozoic basement as obtained from 3D surveys (solid lines) and/or from 2D surveys (dotted line) of the area studied.

It is distinctly seen that:

- strike-slip fault axes are grouped into two diagonal systems: $\sim$ SW-to-NE and $\sim$ SE-to-NW

- not a single north-south or east-west strike-slip axis was detected

- axis azimuths of the same direction are not strictly coincident; they may vary within a $10-15$ range

- average azimuths of the same direction for the detected diagonal systems are practically symmetrical to the meridional axis and form a roughly 80 angle

- the strike-slip fault axes do not form a single strike-slip or strike-slips extending for hundreds of kilometers, but rather form fragmentary systems, each of them with a length of a few tens of kilometers - as can be seen also in the dip maps and from SSFS manifestation zones on 2D and 3D seismic data.

A tectonophysical explanation for the observed strike-slip faults on the Paleozoic surface is given by their striking similarity to the model of a "clean"* strike-slip process as described by Hoeppener et al. (1969). Figure 9 is an illustration, borrowed from Hoeppener's work, and shows the position of shear fractures in a homogeneous medium exposed to a one-sided horizontal compression. Note that the generated deformations create a system of diagonal shear fractures forming a steep angle of about 80 oriented toward the maximum compression axis. This situation is very similar to that seen in Fig. 8.

\footnotetext{
* Tectonophysics distinguishes two types of shifts: "simple" shift when axes of compressional or tensile horizontal stresses are displaced perpendicularly, rather than located on a single axis. Then, elementary rock volumes are exposed to bending and rotation. "Clean" shift occurs when axes of compressional or tensile stresses are located on a single axis and compress or extend elementary rock volume.
} 


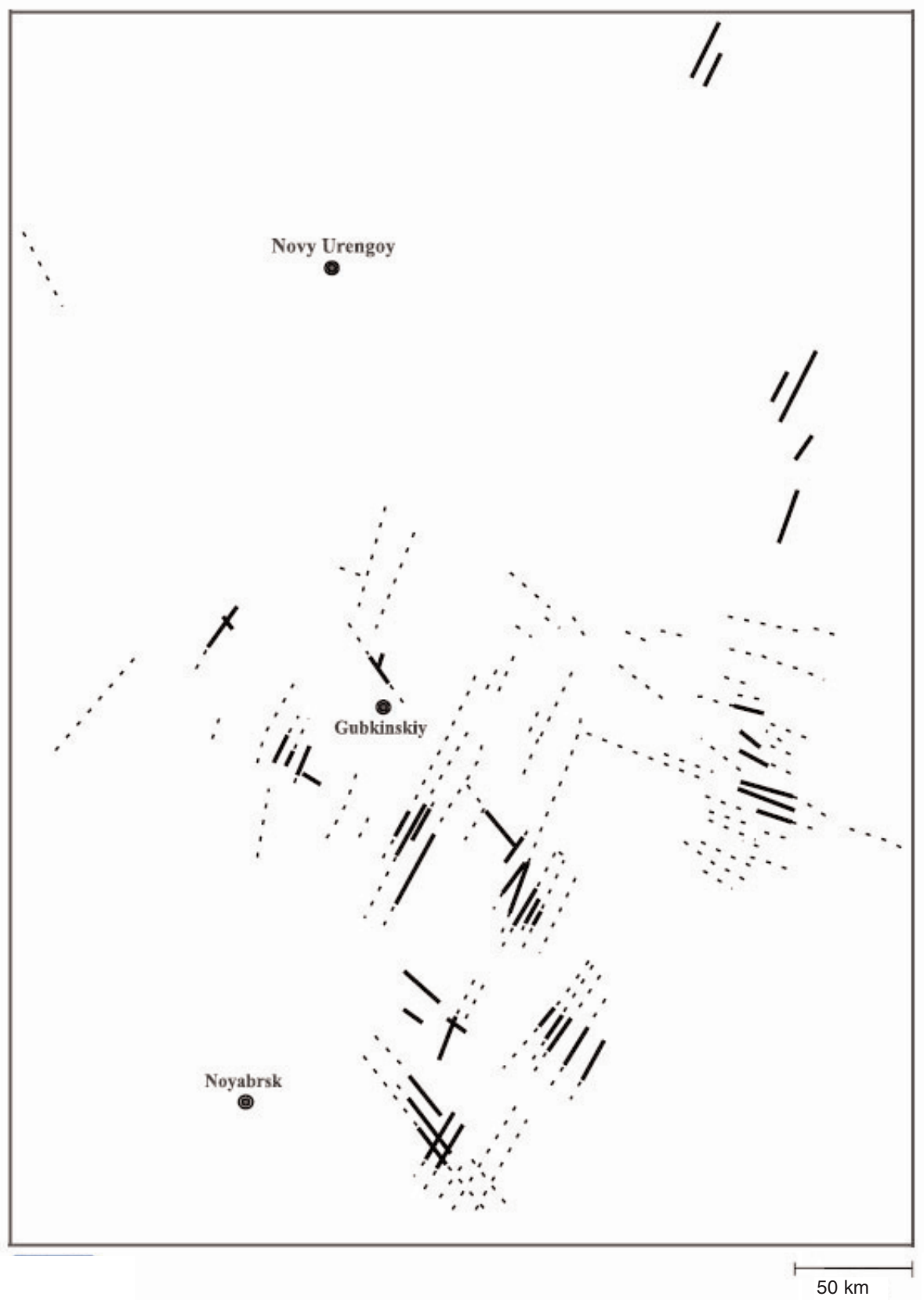

Fig. 8

Schematic spatial positions of Paleozoic strike-slip dislocations in the study area. Two diagonal shear fault systems - SE to NW and SW to NE - are seen at an average angle of $80^{\circ}$ to each other 


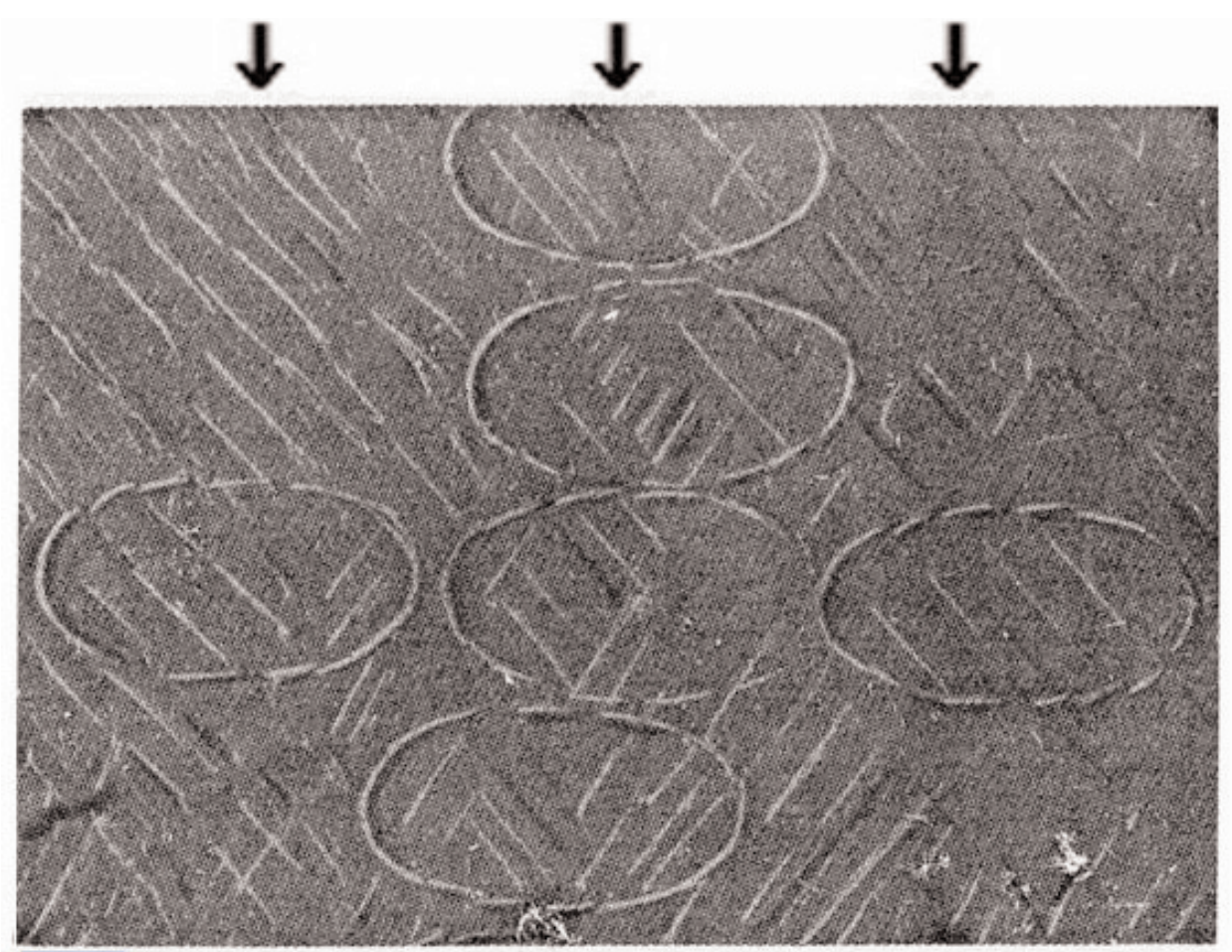

Fig. 9

Physical modeling of a "pure" strike-slip fault (Hoeppener et al. 1969). As a result of horizontal compression along the surface shown with arrows, the model was deformed (circles drawn on the surface turned to ellipses) along with formation of a system of diagonal shear fractures at an acute angle of $80^{\circ}$ along the direction of compression axis. This image is similar to the system of basement shear fractures shown in Fig. 8

Thus the diagonal shear fractures in the Paleozoic section of the study area can be explained by a powerful and (geologically) short-term pulse of the meridional earth crust compression in the central West Siberian plate at the Tertiary/ Quaternary boundary. This has generated a system of shear fractures in the consolidated earth crust. Each of these shear faults (or the most intense of them) was responsible for forming a complex system of deformations in the overlying Meso-Cenozoic sedimentary sequence. A distinctive feature of these deformations is a series of en-echelon faults above the shear fractures in the basement.

To predict the presence of SSFS in the rest of the West Siberian basin, the structure map of the Albian-Cenomanian (Kontorovich and Nesterov 2000; Fig. 10) has been used. This map clearly shows a spectacular chain of NNW-striking linear highs (310-320 azimuth). In all of such linear highs within the study area (red rectangle) (Chasel, Kharampur, Vynga-Yakhi, Yety-Pur, Gubkin) strike-slip dislocations have been identified. This observation provides weighty grounds to suggest that other linear highs along this axis to the north and to the south may 


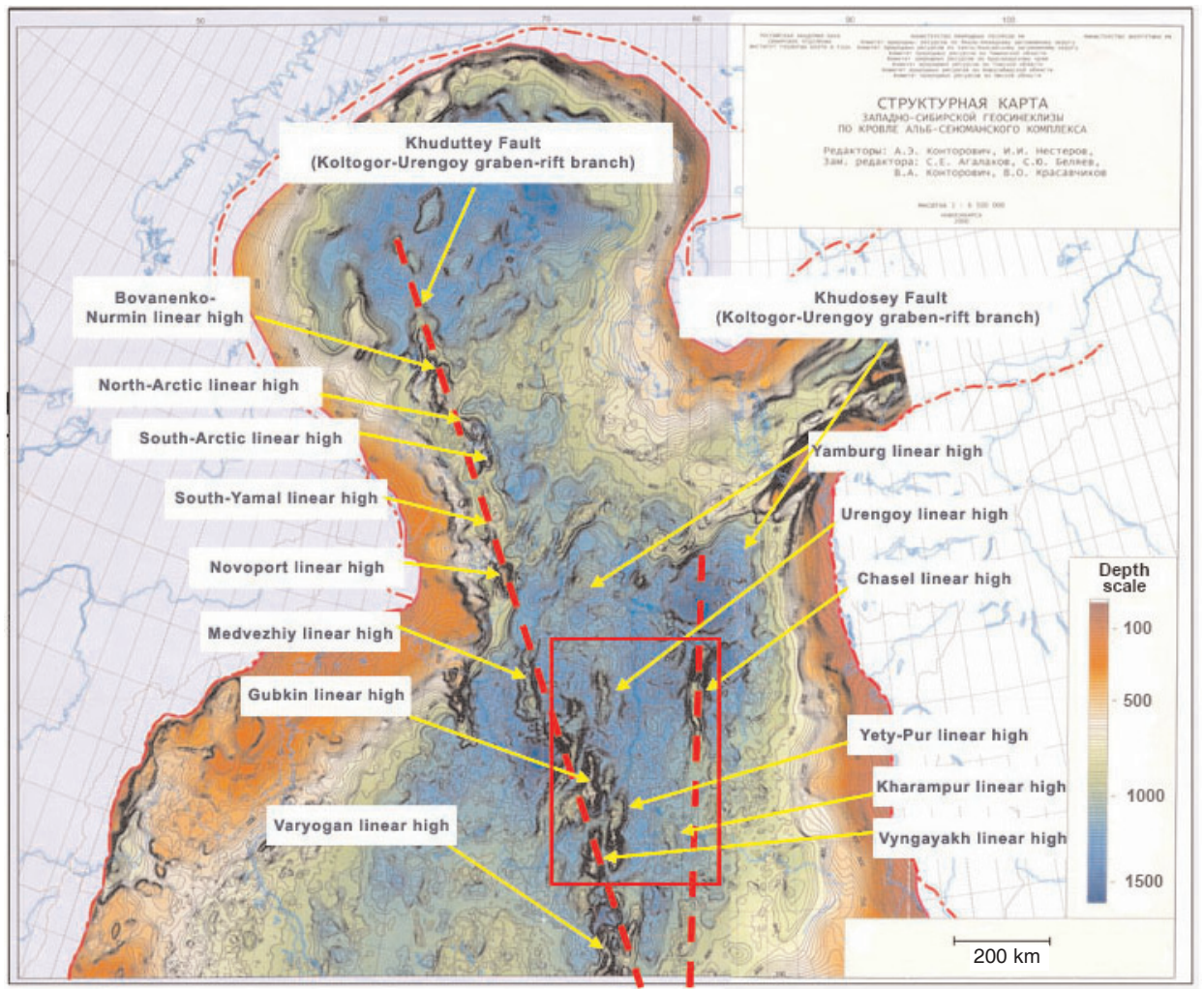

Fig. 10

Structural map of the West Siberian geosyneclise at the top of the Albian-Cenomanian section (edited by Kontorovich and Nesterov 2000). Regional supra-order, linear mega-structures (Khuduttey and Khudosey Faults) are associated with and complicated by basement SSFS. A rectangle encompasses areas discussed in this study

have experienced strike-slip dislocations. A tentative analysis of data from areas south of the study area (Var-Yogan linear high, Tagrin area and others) and north of it (Medvezhiy linear high and adjacent areas) fully confirms this assumption. On the structure map of the Albian-Cenomanian, this structural line is expressed as a chain of en-echelon-type juncture of the above-mentioned linear highs to the West Siberian tectonic suture linked with the Khuduttey branch of the KoltogorUrengoy graben-rift (Surkov and Zhero 1981). It is important to note that west of this chain of linear highs, neither 3D data nor 2D data give grounds to believe that strike-slip fault structures (SSFS) spread westward; therefore this chain of linear highs may be regarded as the western boundary of the SSFS development zone. Another structural line, expressed as a chain of en-echelon-type junctures of the Kharampur, Chasel, Russkiy, Tazov and other linear highs that continue towards the Bolshekhet depression and Yenissei-Khatanga downwarp, is 
presumably linked with the Khudosey graben-rift fragments that were activated during the neo-tectonic phase. This structural line may be presumed to form the eastern boundary of the SSFS development zone.

The southward spreading of SSFS along this structural line is suggested by a number of indirect indications on the structures of the Bakhilov, Alexandrovskiy and Mezhdurechenskiy linear highs (Bakhilov, Khokhriak, Permiak and KolikYogan highs) in the Vasyugan oil and gas-bearing area (Khanty-Mansi Autonomous Area). SSFS also manifest themselves in the Samotlor oilfield located on the Nizhnevartov dome (Gallyamov et al. 2004).

These two axes form a fan that opens up to the north. The northern boundary of the strike-slip dislocations is still undefined; it is assumed is that the vast areas of the West Siberian north and Kara Sea, where giant gas and oil-gas fields have been discovered, have also been subjected to intense strike-slip deformations of the earth's crust.

All of these prove the regional nature of processes that activated basement strike-slip faults in West Siberia during the Late(st) Cenozoic. Depending on the SSFS maturity, various structural indicators for strike-slip deformations can be mapped in the West Siberian sedimentary cover - ranging from en-echelonshaped drag folds and early shear fracture systems (during early development phases) to linear suture zones of deformations and rock mass discontinuities in the sedimentary cover (during late development phases). The majority of studied prospects have indications characteristic of early SSFS development phases, although some of them (Yety-Pur, North Komsomol) reach later phases in their development. This is a notional gradation of strike-slip fault structures, and, as will be shown below, the physical nature of differences in the structural style of SSFS lies in the intensity of the strike-slip deformations in the basement complex.

\section{Structural style of the SSFS}

The age of the youngest rocks subjected to deformations has been used to date the age of the SSFS. Figure 11 shows 3 vertical sections from a seismic data cube of the Yety-Pur area (refer to the Yety-Pur linear high in Fig. 10) where faults are clearly seen to cut through the entire Jurassic, Cretaceous and Tertiary, and fade out at the Tertiary/Quaternary boundary. Thus, the SSFS is extraordinarily young in this area; i.e. it is a typical neotectonic event spanning the entire section. However, in the same Yety-Pur area, and in some other areas as well, a series of dislocations, deforming the Jurassic and lower part of the Cretaceous only, can be observed (e.g. transversal en-echelon zone in the North Komsomol area in Fig. 2 that crosses the main SSFS system). These dislocations, possibly with very low strike-slip separation (fracturing!), may have affected younger rocks as well, but with displacements below seismic resolution.

On the basis of the physical modeling, a more probable explanation for the different depths of SSFS extent is the magnitude of the strike-slip separation in 


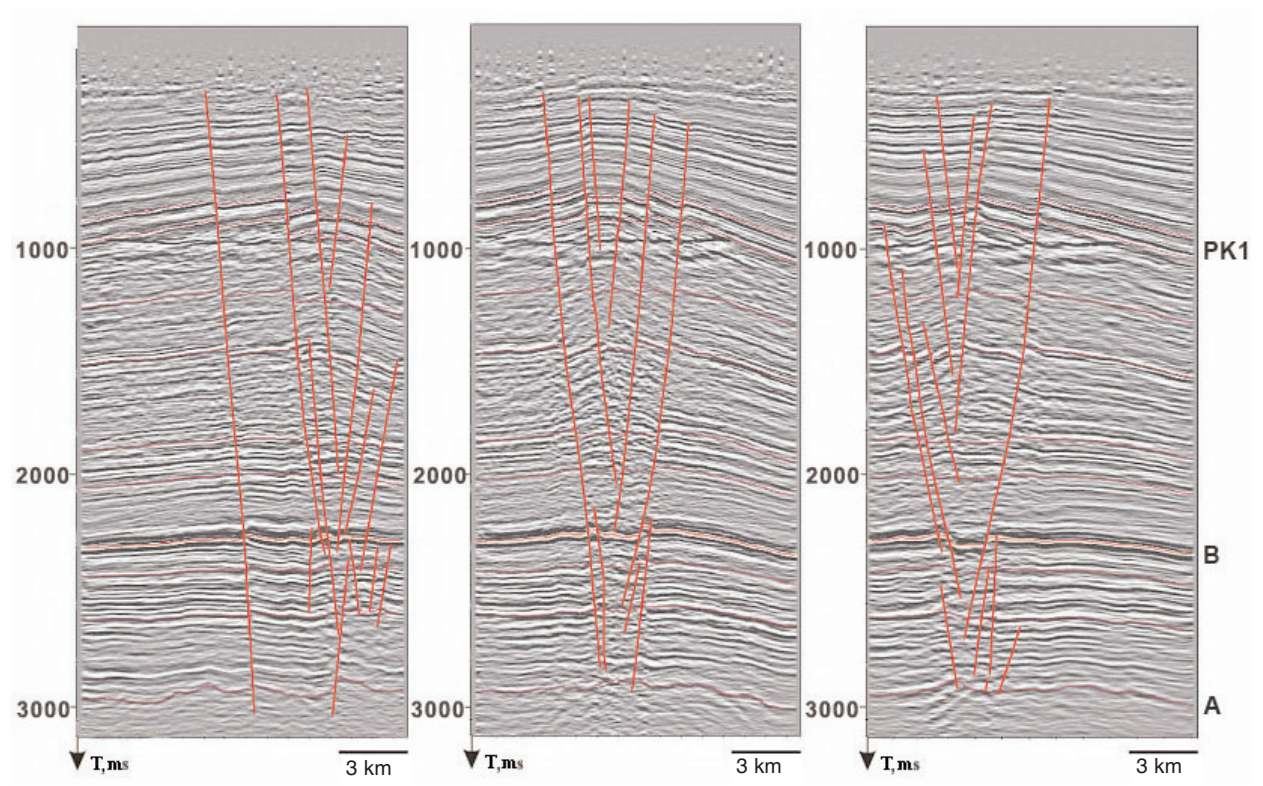

Fig. 11

Vertical east-west cross-sections from a 3D seismic cube featuring the northern dome in the Yety-Pur area complicated by faults that penetrate the entire stratigraphic interval from the Paleozoic basement up to base Quaternary

the Paleozoic basement, rather than different age of deformations. With very low strike-slip fault separation magnitudes within the basement, deformations in the plastic-elastic cover were not able to affect (activate) the entire sedimentary rock section, and faded out within that cover. Note also that the most widespread zone is able to deactivate deformations is the Lower Cretaceous clinoform section. It overlies Horizon B (top Jurassic) and contains a substantially higher ratio of plastic shale as compared with the overlying and underlying sections with a relatively high percentage of sandstone.

The spatial geometry of SSFS is rather complicated. The Sylvester model (Fig. 12, after Sylvester 1988) is an adequately simplified representation of the observed geometry. En-echelon dislocations reach maximum magnitudes in the upper part of the section (e.g. in the Yety-Pur area, they reach $5 \mathrm{~km}$ in length). Fault plane dip angles in the same upper part of the sections are moderate $\left(45^{\circ}-50^{\circ}\right)^{*}$. Closer to the basement the en-echelon lengths are reduced and dip angles become steeper $\left(70^{\circ}-80^{\circ}\right)$. En-echelon strike azimuths approach the basement fault azimuth. This type of faults forms "palm-tree-" and "tulip-"shaped structures and fits with the case when an en-echelon system is formed under

* In Figs 3 and 11, the sections are exaggerated (= squeezed horizontally), so, the echelon dip angles look steeper 
conditions of extension or compression in a direction perpendicular to the basement strike-slip fault axis (Sylvester 1988).

The distances between faults that form echelons in the study area range from $250 \mathrm{~m}$ to $2,500 \mathrm{~m}$. The vertical throw of en-echelon dislocations reaches a maximum of $100 \mathrm{~m}$ and more at the top Cretaceous.

It is very challenging and of practical significance to assess strike-slip fault separation magnitude along top basement. Unfortunately we have not found evidence of strike-slip faults with an opportunity to determine the horizontal displacement along them. Of the experimental models, the most credible data are in Naylor's work (Naylor et al. 1986) indicating that enechelon dislocations, similar to those observed, are formed when horizontal displacements are equal to 0.3 to 0.8 of the sedimentary cover thickness. For the geologic conditions under discussion, this range is $0.8-3.0 \mathrm{~km}$. Such dislocations caused deformation of the entire sedimentary section up to paleosurface that existed at the time when the strike-slip faults developed. In cases when en-echelon deformations affect only part of the section, for example the Jurassic only, it may be assumed that strikeslip fault separation magnitude along top basement is of tens to a few hundreds of meters.

In order to estimate the width of dislocations (detachments) Fig. 13 demonstrates a portion of a seismic profile where layers rotate into a rupture (detachment) to a depth of about $40 \mathrm{~m}$ at the top Upper Cretaceous level (Horizon PK-1). This phenomenon is possible if the width of the respective fracture is at least several meters or even few tens of meters. A similar situation can be observed in a number of other areas.

Vertical detachments create unique channels (paths) for vertical fluid flow at a certain phase (apparently at an early phase), confirmation of which will be seen when examining SSFS-complicated structures for oil and gas presence. Principles of geomechanics tell us that such channels cannot exist for long in the sedimentary cover. When basement blocks cease moving, the displacement stress drops in the sedimentary section, and lateral compression will close the 


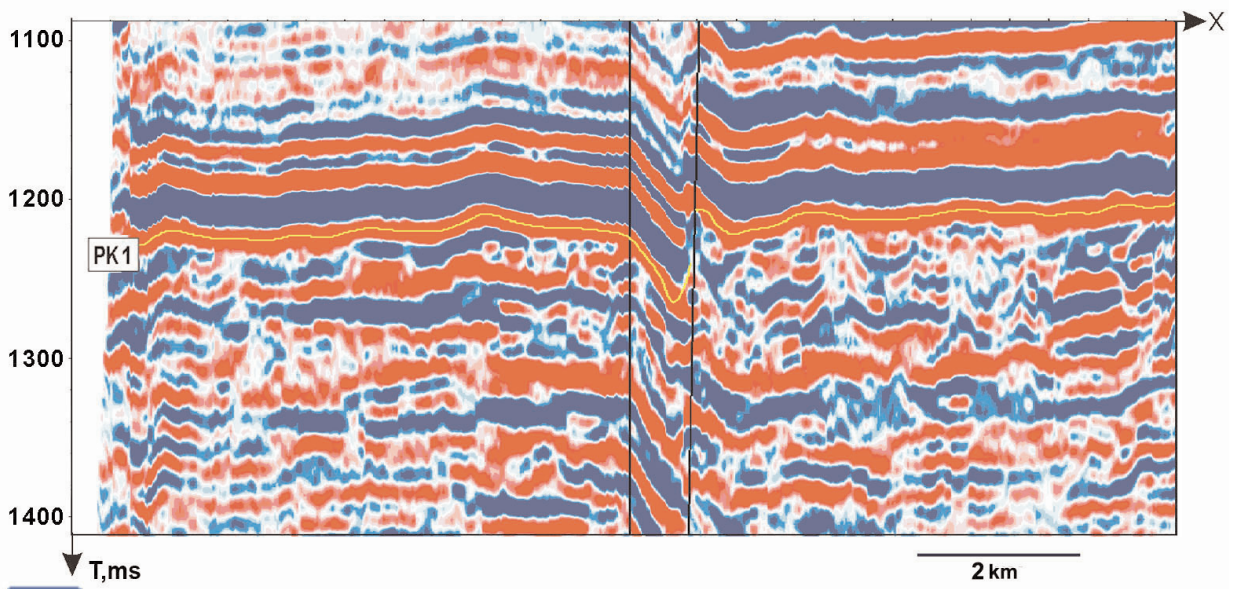

Fig. 13

A portion of seismic section illustrating Upper Cretaceous rotation (tilting) of layers into an enechelon-shaped detachment fracture to a depth of about $40 \mathrm{~m}$. The width of the fracture zone is $800 \mathrm{~m}$

permeability "pipes", partly or completely, thus reducing or completely eliminating any (vertical) fluid migration. This theory is proved by the preservation of giant Cenomanian gas accumulations in a number of SSFSfaulted structures. Such a situation is exemplified in Fig. 14 where a (sub) horizontal gas-water contact is perfectly seen to delineate a thick, massive pool at the northern dome of the Yety-Pur structure intersected by a series of en-echelon faults. The strongly reversed nature of the faults indicates the presence of compressive forces. Note, however, that this example does not exclude the possibility of a reduced gas migration upward along certain faults. Therefore a strict environmental control should be imposed over such fields, especially when oil production is in full swing and wells disrupt the permafrost zone - the last good seal before the gas reaches the recent surface.

\section{Structure-forming role of SSFS}

The impact of SSFS on the recent structural pattern can be studied at two scales: (1) in geologic sections and hydrocarbon deposits within those sections, i.e. we study structures of the 1st, 2 nd, and 3rd order for which Paleozoic basement strike-slip faults themselves are responsible, or (2) block arrangement of some of the structures and non-structural traps where a decisive role is played by en-echelon faults and deformations in the sedimentary cover.

As noted above, strike-slip faults in the basement are fragmentary: they form two diagonal systems (Fig. 8) where each system consists of fragments that are tens of kilometers long (strike-slip terminations can be seen in a number of areas, e.g. in Fig. 6-Map 4). Fragments with the same direction/orientation are spaced 
tens of kilometers apart. Horizontal separation of displaced basement blocks is, as shown above, of a magnitude ranging from hundreds of meters to few kilometers. The basement strain generating this situation should apparently be released along the vertical direction, primarily toward less overburden, that is, toward the sedimentary cover, thus forming highs and downwarps there. In terms of age, these structures should be contemporaneous with the strike-slip faults.

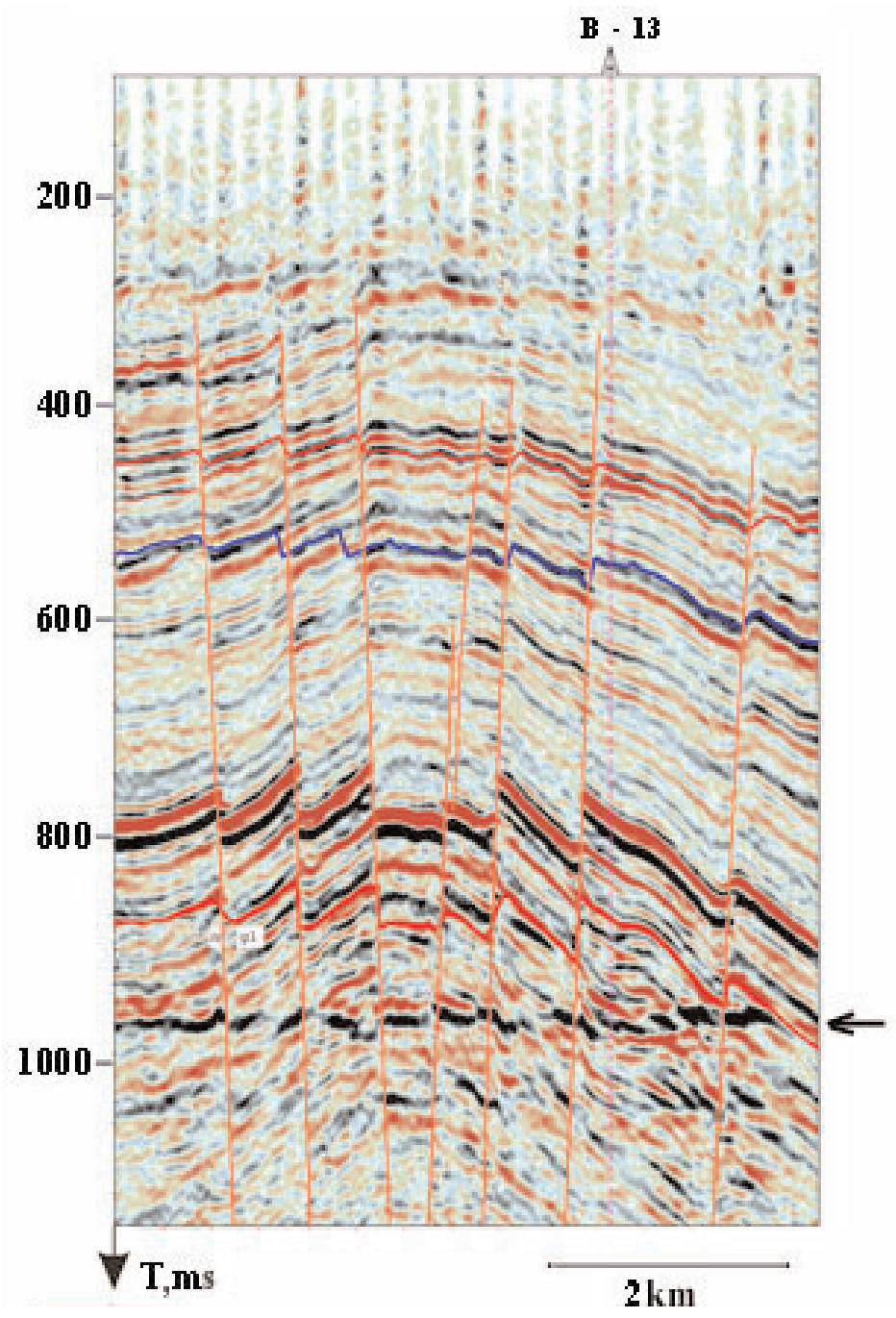

Fig. 14

Seismic east-west section through the center of the northern dome in the Yety-Pur Field showing a clear image of horizontal/flat gas-water contact (indicated with an arrow) against the background of a clearly demonstrated system of en-echelon faults 
To verify this hypothesis, paleo-reconstructions were undertaken in a number of areas. They convincingly showed that quite a few structures of the 2 nd and 3 rd order along top Upper Cretaceous are very young and were formed in the Cenozoic as a consequence of strike-slip faults in the Paleozoic basement. We use the example of the Yety-Pur linear high to demonstrate this. This linear high in its present-day form consists of two domes with totally different development histories. This can be perfectly understood by analyzing differences in interval thicknesses given in Table 1 .

Table 1

\begin{tabular}{|l|c|c|c|}
\hline \multicolumn{1}{|c|}{ Section Interval } & $\begin{array}{c}\text { Southern Dome } \\
(\mathrm{m})\end{array}$ & $\begin{array}{c}\text { Northern Dome } \\
(\mathrm{m})\end{array}$ & $\begin{array}{c}\text { Interval Thickness } \\
\text { Increment }(\mathrm{m})\end{array}$ \\
\hline $\begin{array}{l}\text { - Top Basement A } \\
\text { - Top Jurassic B } \\
\text { A - B }\end{array}$ & 1080 & 1420 & -340 \\
\hline $\begin{array}{l}\text { - Top Jurassic B } \\
\text { - Top Cenomanian PK1 } \\
\text { B - PK1 }\end{array}$ & 2053 & 2109 & -56 \\
\hline $\begin{array}{l}\text { - Top Cenomanian PK1 } \\
\text { - Paleocene Boundary S2 } \\
\text { PK1 - S2 }\end{array}$ & 380 & 352 & 28 \\
\hline $\begin{array}{l}\text { - Paleocene Boundary S2 } \\
\text { - Earth Surface - P } \\
\text { S2 - P }\end{array}$ & 390 & 344 & 46 \\
\hline \hline
\end{tabular}

When the key Bazhenov horizon B (top Jurassic) was deposited at top Jurassic, the southern dome had already been formed as a syn-sedimentation high, while in place of the northern dome there was a downwarp. The Jurassic deposits in the northern dome are $340 \mathrm{~m}$ thicker than in the southern dome. During the Lower and Middle Cretaceous, by the time of Cenomanian transgression that leveled the basin, the southern dome continued to grow but at an appreciably lower rate, while the northern downwarp continued to exist but the thickness surplus in the north is as low as $56 \mathrm{~m}$. During the Cenozoic time the situation changed abruptly. Along with the continued slow growth of the southern dome, the northern dome began to grow rapidly. By that time the key S2 reflector had formed in the Paleocene and the thickness of the southern dome was $28 \mathrm{~m}$ more than that of the northern dome. The northern dome experienced its fastest growth rate between horizon $\mathrm{S} 2$ and the present-day earth surface. The thickness of the sediments deposited in this time interval over the southern dome is $46 \mathrm{~m}$ larger than that over the northern dome. It is precisely in this time interval that strike-slip dislocations formed: more powerful at the northern dome (see Fig. 11) and less powerful but more numerous at the southern dome and in the interdome zone. 
Thus it can be stated that strike-slip faults in the basement have considerably influenced the present-day structural pattern of central West Siberia.

Local SSFS plays no minor role in forming a block architecture of the entire sedimentary cover and in generating complex plicate deformations. Plicate deformations are developed by a combination of the strike-slip faults themselves with a simultaneous transversal compression and extension in the sedimentary

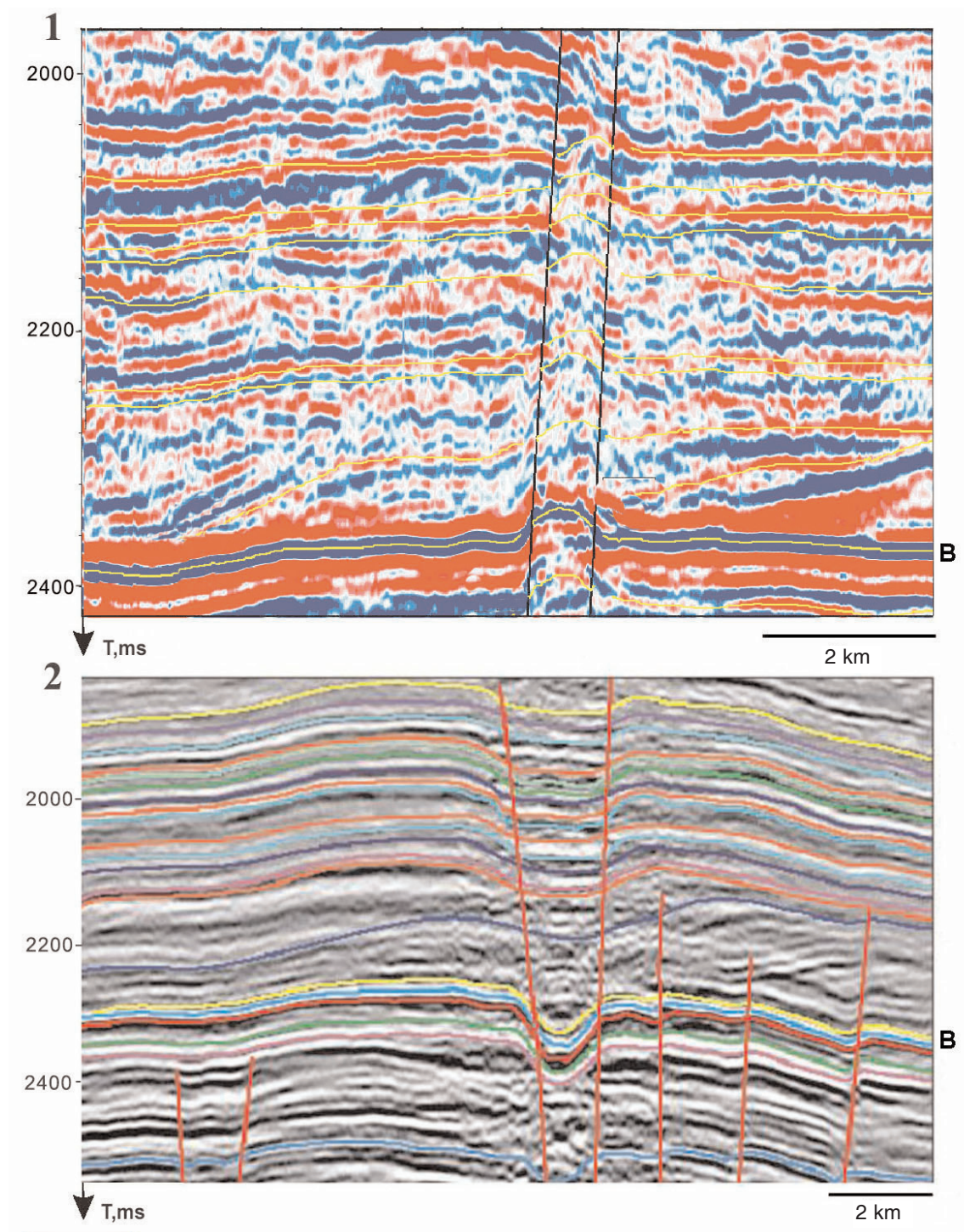

Fig. 15

Deformations in the Bazhenov horizon triggered by strike-slip movements in the basement complex

1) under transversal compression and 2) under transversal extension 
section. Examples of such deformations are shown in Fig. 15 where the upper (1) section illustrates a case where compression and folding of the Bazhenov horizon takes place. Section 2 presents a case when a strike-slip fault, combined with transversal extension, forms a downwarp in the Bazhenov horizon. In both cases this zone is characterized by stratal plication and most likely with developing impermeable barriers along the faults intersecting the sedimentary cover.

Deformations of this type essentially changed the overall structural style of exploration areas. Figure 16 is a structure map along the top of the Bazhenov horizon at the northern dome in the Yety-Pur area. Here the central graben, 0.5 to $1.0 \mathrm{~km}$ wide, is clearly seen to have formed above the strike-slip fault axis. It can also be seen that the entire dome structure is deformed. The eastern flank of the structure is displaced southeastward, while the western flank is displaced

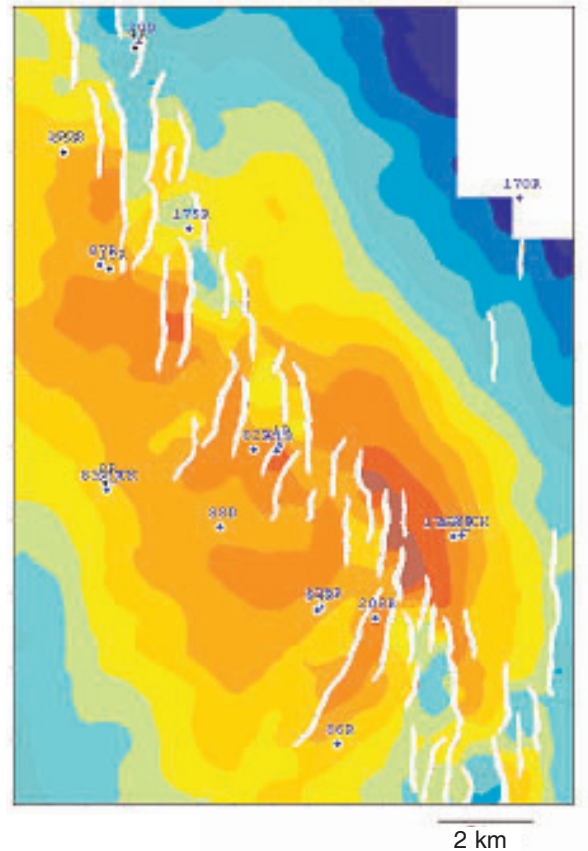

Fig. 16

Structural map of the top Bazhenov horizon Jurassic/Cretaceous Boundary) on the northern dome in the Yety-Pur Field. Note that the axial zone of en-echelon faults forms a graben, up to $1 \mathrm{~km}$ wide and down to $50 \mathrm{~m}$ deep. The highest parts of the structure are displaced $4-5 \mathrm{~km}$ at either side of the axial zone. En-echelon faults form a system of blocks at either side of the central graben northwestward and the displacement is more than $4 \mathrm{~km}$.

It was for the first time in the YetyPur area that a very special type of fault was identified (Fig. 17) that could be referred to as different-direction faults because they are characterized by a different displacement direction of the same block below and above a neutral surface (NS). In our case this NS is associated most frequently with the horizons of the (clinoform) Achimov beds prograding from the east to the west and overlying the Bazhenov horizon. Above the NS the fault is classified as a downthrown (normal) fault, whereas below the NS the same fault acts as an upthrown (reverse) fault. At the neutral surface the displacement is zero, while upsection the displacement grows (as a downthrow) reaching a throw of $40 \mathrm{~m}$ at the M1 horizon (Middle Cretaceous), and it also grows down from the NS but as an upthrow, and is $20 \mathrm{~m}$ at horizon B (top Jurassic) level. As a consequence of the deformations a total of $60 \mathrm{~m}$ thickness difference has developed at either side of the fault within the B-M1 section. 


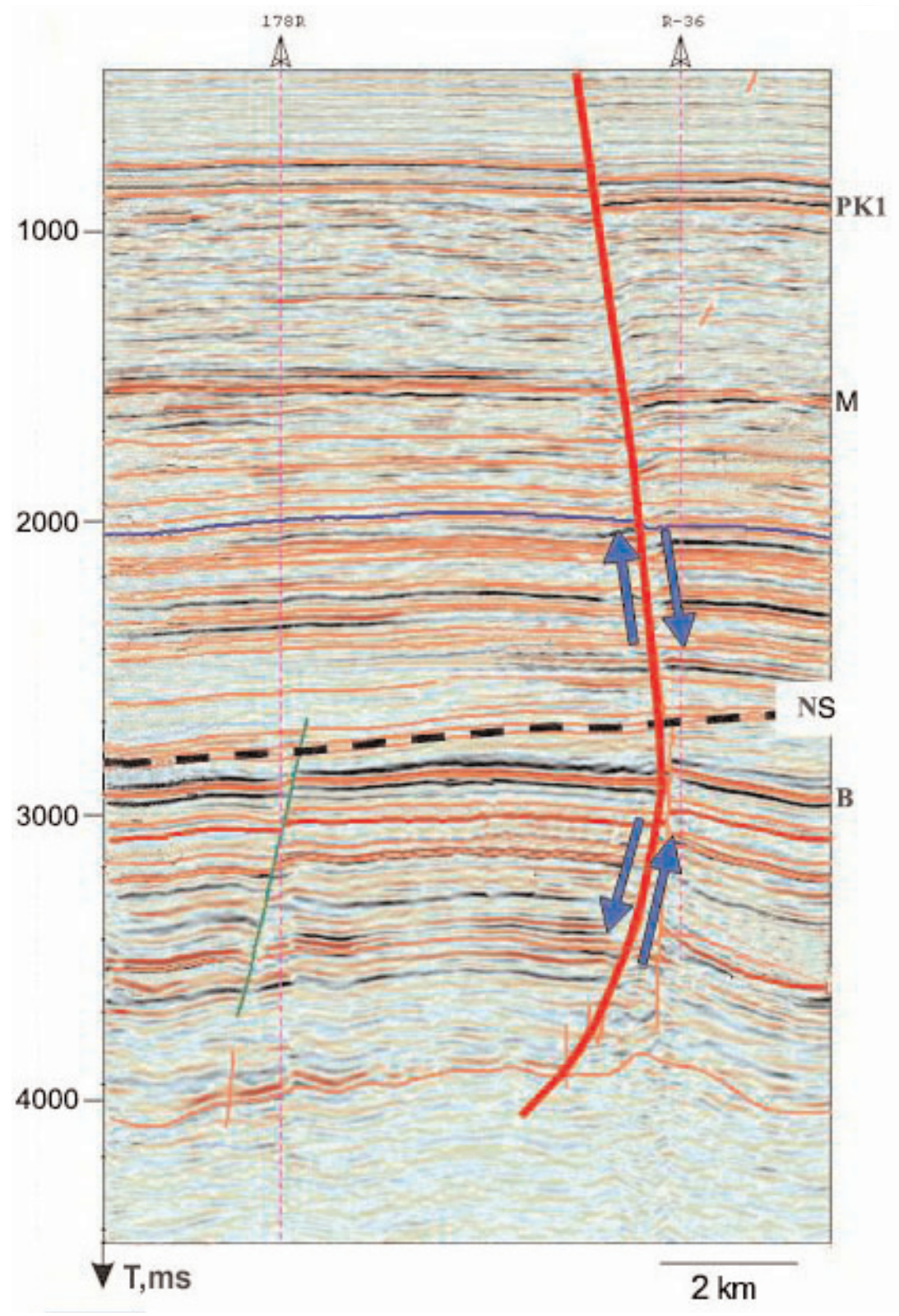

Fig. 17

Example of a different-direction fault: the "downthrown" block/hanging wall on the top of the Bazhenov horizon is west of the fault, while in the Cretaceous section the same western side is the "upthrown" block (footwall) with a neutral (no-displacement) zone in the shaly clinoforms of the Achimov horizon. Thickness difference over either section of the different-direction fault reaches $60 \mathrm{~m}$ 
Therefore, on the right side of the different-direction fault the thickness is reduced on account of plastic squeeze and compaction of rocks, without any disruption of stratification or any sedimentation break. On the other side of the fault surface the rocks are injected and decompacted on account of extension.

These examples allow understanding the possible reasons for the existing misties and provide grounds for revising debatable moments in well-to-well correlation of horizons inside the SSFS compression wedges.

\section{SSFS and oil-and-gas presence}

Formation of vertical (fluid flow/migration) channels within SSFS can be the explanation why multi-layer hydrocarbon fields with numerous productive zones were formed throughout the entire sedimentary sequence affected by strike-slip dislocations. Fields such as Yety-Pur, Komsomol, North Komsomol and others, associated with SSFS, consist of 30 to 40 and more productive zones, starting with Lower Jurassic up to the Tertiary. In addition there is a complex alternation of gas-capped oil, under-saturated oil and non-associated gas beds, indicating the pulsation of migration and of trap filling processes.

A very characteristic montage of oilfields from the east of the Khanty-Mansi Autonomous Area is shown in Fig. 18 that was prepared by the Khanty-Mansi Autonomous Area Shpilman Science Center in 2004 (Khanty-Mansi Autonomous Area Geology and Presence of Oil and Gas Atlas 2004), and which indicates the position of the oil and gas deposits within the stratigraphic column. 37 fields, of the Nadym-Pur and Vasyugan oil-and-gas-bearing areas are included in this montage. All of them have productive zones close to the Bazhenov Formation at the Jurassic and Cretaceous boundary, and are partly located on the southern extension of the SSFS zone described above. It can be seen that out of 37 fields there are six where the productive interval is not restricted to the near-Bazhenov layers, but extends significantly higher up in the stratigraphic column, reaching the upper part of the Cretaceous with a multitude of productive beds. These fields are Varyogan, Van-Yogan, Tyumen, Novo-Agan, Upper Kolik-Yogan and Severnoye (Northern).

The publication neither highlights nor explains this situation. However, we can say with much confidence that these fields fall within the SSFS zone. 3D surveys have already confirmed this fact in some of the areas (e.g. Upper-Kolik-Yogan), and subsequent 3D surveys will undoubtedly prove this in other areas as well. Moreover, new 3D surveys may be expected to bring out new SSFS zones and provide firm grounds for re-evaluation of the Vartov and Pokur Formations of the fields in the above-mentioned field montage (Fig. 18) in order to discover bypassed hydrocarbon deposits there.

A vast area of the northern part of West Siberia that includes a good number of giant Cenomanian gas fields, where SSFS should be actively developed, deserves special attention. According to factual data, a multitude of oil and gas deposits 
can be expected below the Cenomanian in the study area. Some of them are already discovered or are under study, but the full potential of the Jurassic, the Lower and Middle Cretaceous is still far from being completely revealed. The geologic and structural model of the respective basins needs to be totally revised

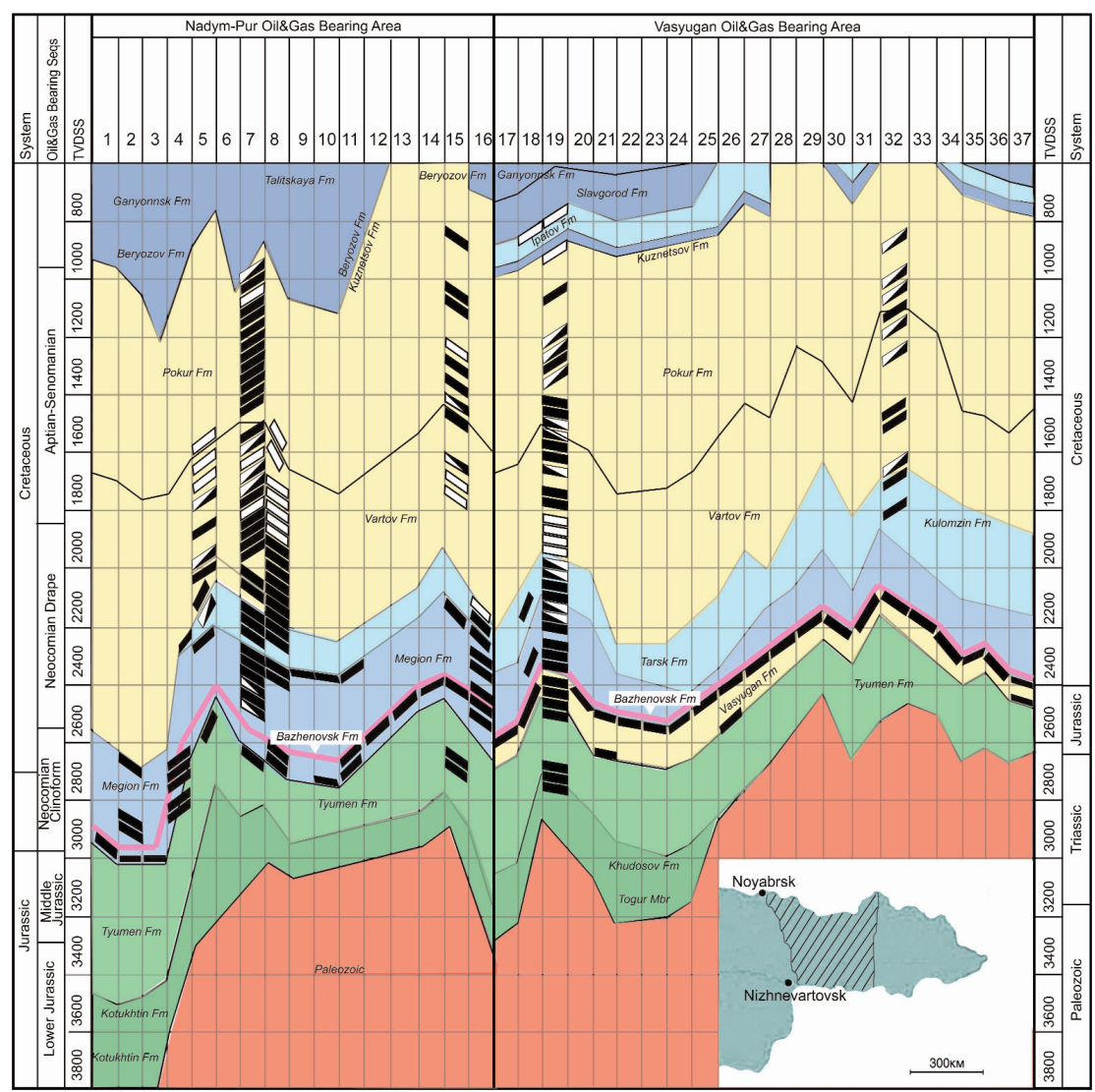

$\sum_{-\mathrm{c}}^{-\mathrm{a}}$

Fig. 18

A montage of hydrocarbon fields present in the Nadym-Pur and Vasyugan petroliferous areas (hatched) of the Khanty-Mansi Autonomous Area (Khanty-Mansi Autonomous Area Geology and Presence of Oil and Gas Atlas 2004). Fields with very thick stratigraphic interval with numerous oil and gas deposits (from the Bazhenov horizon to the top of Cretaceous) are understood to be affected by basement-strike-slip-fault-generated dislocations. Fields: 1. Selivonik, 2. Vyngapur, 3. Valkonin, 4. North Varyogan, 5. Varyogan, 6. Ay-Yogan, 7. Van-Yogan, 8. Tyumen, 9. East Tyumen, 10. Nikolskoye, 11. East Nikolskoye, 12. Stavropol, 13. West Novo-Molodyozhnoye, 14. Novo-Molodyozhnoye, 15. NovoAgan, 16. Tagrin, 17. Bakhilov, 18. Varynch, 19. Upper Kolik-Yogan, 20. Suslikov, 21. North Khokhryakov, 22. Vonter, 23. Malosikorskoye, 24. Enitlor, 25. South Enitlor, 26. Khokhryakov, 27. KolikYogan, 28. Arigol, 29. Maksimkin, 30. Inin, 31. East Okter, 32. Severnoye, 33. Vakh, 34. Koshil, 35. Kottun, 36. Kir, 37. Permyakov, productive: $\mathrm{a}$ - oil, b - gas, c - oil-gas 
by mapping the SSFS zones and by identifying fields with large oil and gasbearing intervals associated with the SSFS zones.

In the territory studied, all large Cenomanian hydrocarbon deposits are discovered in structures with proven strike-slip dislocations that intersect the

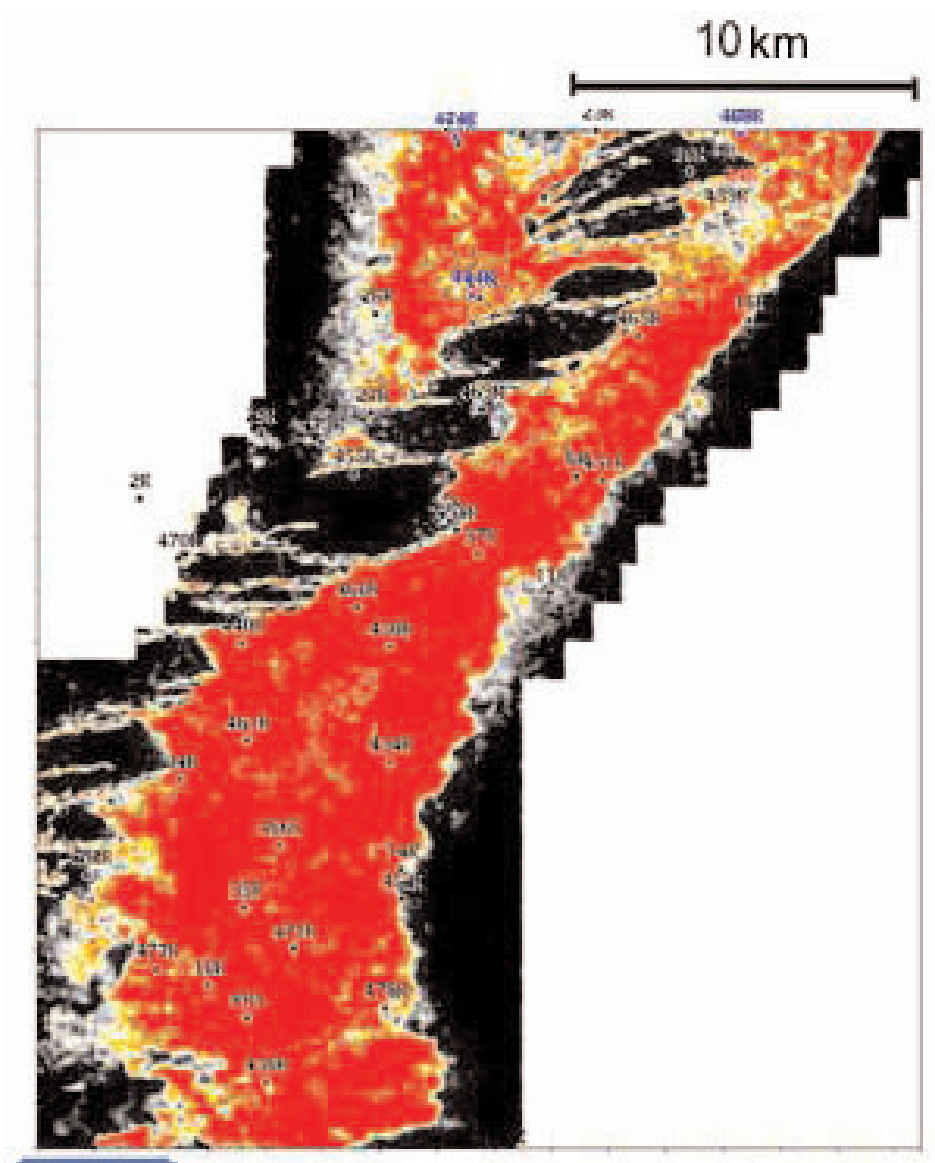

Fig. 19

A Cenomanian gas pool in the North Komsomol field clearly outlined by a seismic amplitude anomaly on a reflection map

complete Cretaceous section. The seismic amplitude map in Fig. 19 shows an amplitude anomaly that clearly outlines a giant gas deposit at the top of the Cenomanian associated with a system of en-echelon faults in the North Komsomol area. Note that the seismic survey distinctly identified gas anomalies in this field and higher up in the stratigraphic column, in a few thin Tertiary sand beds that are intersected by echelons of strike-slip dislocations. It is also 
noteworthy that Fig. 14 shows a Cenomanian gas deposit (in the Yety-Pur field) that is formed on an SSFS.

Further understanding of the role the SSFS play in northern West Siberia is provided in a splendid analysis of the geology of the Yamal Peninsula and adjoining areas presented in a book by Skorobogatov (Skorobogatov et al. 2003). The authors of the book plausibly describe appreciable development of complex disjunctive dislocations in many of the giant fields (Novoport, Tarko-Sale, North Urengoy, Nydin, Bovanenko, Kharasavey, Medvezhye, Amsovey, Tazov, Geofizicheskoye and others) in the north of West Siberia. They also mention fields that are located south of those listed above and are discussed in the present article (Yety-Pur, North-Komsomol and Kharampur), and where we have proved the connection between faults in the sedimentary cover and the strike-slip faults in the Paleozoic basement. The authors of the book refer to the immense stratigraphic interval of oil and gas presence extending from the top of the Paleozoic to the top of Cretaceous and containing tens of oil and gas deposits in structures affected by disjunctions. In a number of fields (e.g. Novoport and Severnoye), they had determined the age of the youngest dislocation Oligocene-Pleistocene - within the same time interval that we observed for the tectonics in the fields located to the south. The authors date the disjunctive tectonics in other fields older; this may be due to the lack of reliable data available for determining the age of dislocations. They refer to syn-sedimentary faults in the Yety-Pur structure as emerging in the Early Cretaceous. But this is completely inconsistent with fault ages identified as young as Quaternary (Fig. 14).

Apparently, there had been no 3D survey (or, if any, of low quality) in vast areas of northern West Siberia highlighted in Skorobogatov's book by the time the book was ready for publication. This may explain erroneous assumptions such as, for example, the one stating that the tectonic blocks moved primarily along the vertical direction and that there was no hydrocarbon migration from the Paleozoic section. Illustrations of tectonic patterns presented in the book for fields such as Novoport and Neitin do not display any geologically valid fault system.

Nevertheless, an extensive development of disjunctive tectonics in this very zone between the Khudotey and Khudosey faults (Fig. 10), an interrelation between the occurrence of thick oil and gas-bearing stratigraphic intervals and excessive fault blocking and young Neogene-Quaternary dislocations (Fig. 18) all these are established facts documented for many structures in our studies that collectively prove the important role of strike-slip fault structures (SSFS) in the development of the oil and gas deposits over vast territories in the north of West Siberia.

The data presented so far permit the audacious assumption that all Cenomanian gas deposits north of the study area are probably also associated with strike-slip fault structures (SSFS), but that have not yet been detected with confidence-inspiring 3D seismic measurements or mapped. This hypothesis has an immense impact on the petroleum geology of that area, because it will allow 
updating the geotectonic models of hydrocarbon deposits under production and defining new exploration targets.

Another important scientific and practical assumption, based on the analysis of accumulated data, is related to the source rocks, primarily to those of the giant gas resources within the area of SSFS. Complementary to the commonly accepted hypothesis that bituminous shale of the Bazhenov horizon acted as the predominant/exclusive source of liquid and gaseous hydrocarbons in the whole West Siberian Basin, the presence of young vertical migration channels, providing hydraulic connectivity between the Paleozoic basement and the Jurassic-Cretaceous sedimentary cover, permits the statement that there is also a deep hydrocarbon source feeding giant reservoirs via SSFS channels.

\section{SSFS and prospecting, exploration and development of hydrocarbon fields}

New data on an extensive presence of SSFS-generated structures in prospective areas of West Siberia and possibly in the adjoining areas of the Kara Sea, allow new targets for the exploration for oil and gas to be added to the conventional structural and lithologic traps. Those targets are as follows:

- numerous tectonic traps formed as en-echelon faults, both in the upper parts of the Jurassic and in the entire Cretaceous section

- traps in the suture zones of strike-slip faults in the lower (basal) part of the Jurassic strata

- traps in the weathered crust and in the (fractured) basement

These traps can probably be found on the flanks of structural highs and in the lows dissected by SSFS.

In large structures with proven productivity, SSFS mapping can lead to revision of the field models, and instead of a single reservoir of a certain stratigraphic level, a number of isolated blocks could be expected/mapped.

This is precisely what happened to the Yety-Pur field when a 3D survey was completed to study the Jurassic sedimentary section. Instead of a single large trap modeled from 2D seismic and exploratory wells' data, more than 30 smaller hydrodynamic units were mapped. To explore them, an equivalent number of exploratory wells were recommended for drilling. A few of recommended wells drilled to date have produced a considerable amount of oil from the J1 formation at flow rates as high as hundreds of tons of oil per day, thus radically increasing the resource base for this field.

SSFS zones require a non-standard approach to designing well architecture for wildcat, appraisal and production wells. Complex spatial configuration of enechelon faults, presence of disintegration zones and plastic rock flows in the SSFS zones require a careful selection of the drilling locations. This is essential for the early prospecting/exploration phase when potential traps are expected to be discovered at more than one stratigraphic level by drilling a single well in a favorable structural position. Possible traps would be tectonic traps against a 
sealing fault. Consequently, wellbores of prospecting (and exploratory) wells should follow the (spatial) geometry of faults, penetrating the structurally highest part of the respective reservoirs at each level. We have shown earlier that SSFS are far from being vertical; they change their dip angle and azimuth with depth. Therefore an optimally designed well should be a deviated well with a complex geometry/trajectory. Figure 20 shows on its right the position of a well on a seismic map against the contours of the reservoirs. On the left side of the seismic profile, the position of the well is seen as intersecting a fault plane and penetrating potential traps in their highest structural position. The maximum

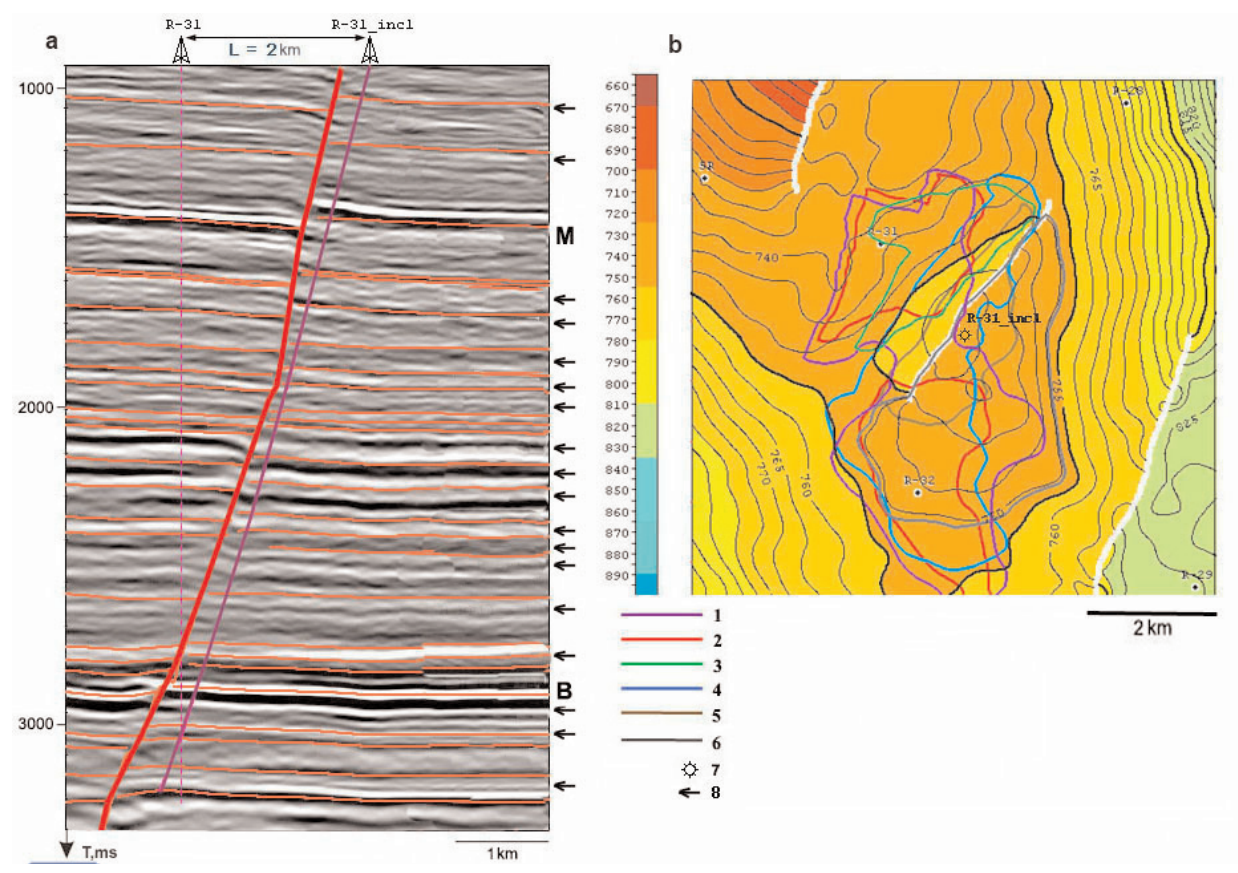

Fig. 20

a) Wellbore geometry design allowing penetration of potential productive horizons of different stratigraphic levels in optimal structural position

b) Outlines of 7 stacked structural closures to be drilled as projected on the structural map of the top of Cenomanian. 1. trap outline at $-3195 \mathrm{~m}$ horizon contour, 2. trap outline at $-3026 \mathrm{~m}$ horizon contour, 3. trap outline at $-2358 \mathrm{~m}$ horizon contour, 4 . trap outline at $-1926 \mathrm{~m}$ horizon contour, 5 . trap outline at $-1926 \mathrm{~m}$ horizon contour, 6 . trap outline at $-751 \mathrm{~m}$ horizon contour, 7 . intersection of well R-31_incl with top PK1 horizon (top Cenomanian), 8. positions of productive beds within the displayed section interval 
deviation at the total depth (TD) of the well (at a Jurassic reservoir level) is $2 \mathrm{~km}$ off the wellhead location.

Designing production well patterns should also be based on true models of reservoir geometry and should honor the reservoir heterogeneity, primarily permeability. The latter is enhanced by fracturing caused by horizontal stresses in the uplifted blocks located in extension zones, and deteriorated by "destruction zones of the reservoirs", i.e. above the major basement faults where physical distortion of the layers and/or plastic deformations may drastically reduce permeability. It is therefore especially important that fault positions and correct parameters of productive beds are honored when designing horizontal sections of wells, when siting injection wells and planning hydrofrac and other geotechnical operations aimed at enhancing ultimate oil recovery.

\section{Conclusion}

The major results and principal consequences of the work highlighted in this article can be summarized as follows:

1. A sizable amount of acquired 3D seismic data has been helpful in proving the presence of a large zone where a very young Neogene-Quaternary system of low-displacement strike-slip faults is developed within the Paleozoic basement in West Siberia, one of the world's largest petroliferous provinces. This zone has caused complex plicate and disjunctive dislocations in the Jurassic-Cretaceous sedimentary cover that accommodates numerous oil and gas reservoirs.

2. The available data allow an SSFS zone to be defined as a fan opening up northward, which acute angle is located around a northern latitude of about 60 . The western limit of the fan is a system of young linear highs (the Medvezhiy, Northern, Vyngayakh, Yety-Pur and Tagrin linear highs) combined in an enechelon style along the conjectural Khuddotey deep fault, while the eastern limit is a system of linear highs including the Chasel, Kharampur, Bakhilov and Alexandrovskiy linear highs found along the conjectural Khudosey graben-rift. The northern boundary of the SSFS development zone is not defined yet, but there are indirect indications that this zone may extend to include the whole West Siberian north and the Kara Sea area.

3. Within the basement section, the strike-slip fault system (SSFS) consists of numerous suture zones, the lengths of which are a few tens of kilometers. They are arranged along diagonal directions: SW to NE and SE to NW. The azimuth angle between them is about 80 on average. The strike-slip separation magnitude at the top basement varies widely from a few meters to a few kilometers. Horizontal dislocations in the basement are responsible for forming young structures of the 2nd and 3rd order in the SSFS development zone; those structures are coincident in age with the time when strike-slip faults were formed. 
4. Strike-slip faults in the basement generate complex plicate and disjunctive deformations in the sedimentary cover. Here a decisive role is played by systems of en-echelon detachment faults that intersect the entire sedimentary section up to the base Quaternary and form highly permeable vertical channels for fluid migration at early development phases in a number of areas. This phenomenon is evidenced by an abnormally wide stratigraphic range of oil and gas deposits (40 and more productive strata) in the majority of oil and gas fields within the SSFS zone. During the Recent phase, when the horizontal stresses ceased, the enechelon faults closed under the impact of lateral compressive forces. Thus, the en-echelon faults may now form permeability barriers for the horizontal flows.

5. Another important consequence of the SSFS development in the JurassicCretaceous sedimentary cover is that large anticlinal structures are broken up by a system of en-echelon faults into series of blocks, each of which may form sets of isolated traps at different stratigraphic levels. Prospecting/exploration of such structures requires a careful study of block boundaries and block structures, and prediction of flow rates and ultimate recovery.

6. The en-echelon fault systems are in principle impossible to map from $2 \mathrm{D}$ seismic surveys. Interpretation of $2 \mathrm{D}$ data usually give incorrect imaging of linear faults parallel to the strike-slip suture in the basement. It is only good quality $3 \mathrm{D}$ seismic data, in-depth-processed with 3D migration procedure, that allow mapping en-echelon faults both areally and vertically at a seismic resolution ultimately able to identify faults with vertical throw of $2-4 \mathrm{~m}$. Note also that strike-slip separation magnitudes are most frequently impossible to be seen on seismic sections. Strike-slip separation estimates mentioned in this article are based on modeling experiments and must be subsequently updated.

7. Prospecting, exploration and development of oil and gas fields located in the SSFS development zone require a special approach to select optimal sites of wildcat, exploratory and appraisal wells, to define the production well patterns, to select an appropriate wellbore geometry and architecture and to select EOR technologies well in advance. The definition of the boundaries and geometry of the structural blocks and identification of fractured zones as higher permeability zones with confidence need a detailed 3D seismic mapping as well.

8. Many issues related to:

- the development of strike-slip dislocations in the West Siberian geosyneclise

- the impact of such dislocations on the formation of oil and gas fields

- on selection of technologies of prospecting, exploration and

- above all, on an effective development of productive zones in a geologic environment of plicate and disjunctive deformations caused by strike-slip tectonics

remain unresolved even today and require all-round and in-depth studies involving basic scientific research.

This publication is expected to inspire more experts to study strike-slip dislocations in other petroliferous regions of Russia and beyond, as the 3D 
seismic imaging as a key tool in the mapping of geotectonically complex structures gains an ever-wider application.

\section{Acknowledgements}

The authors of this article are grateful to the respective management of RosNeft and GazpromNeft for permission to use their companies' seismic data and to a large team of CGE geophysicists who processed and interpreted the seismic data used in this publication. Special thanks should go to Mr. Istvan Berczi for his valuable comments and suggestions, and careful editing of the manuscript.

\section{References}

Belyakov, S.L., G.Y. Bondarenko, V.V. Ivanyuk, A.V. Smirnov 2002: New data on Late Mesozoic strikeslip deformations in the north of West Siberian plate. - Proceedings of Russian Academy of Sciences, Geology Series, 372/4, pp. 510-513. (In Russian.)

Elmanovich, S.S., A.A. Li, A.S. Lavrik 1998: Application of 3D seismic to the Gubkin field in West Siberia. - Geofizika (Geophysics) Journal, 1, pp. 25-32. (In Russian).

Gallyamov, K.K., S.V. Ivanov, S.A. Skrylev, A.V. Bodryagin, A.D. Mitrofanov, Y.D. Kupriyanov, A.P. Shelekhov 2004: Determination of rock fracturing from remote-sensing methods data and geologic-and-PLT data. - Karotazhnik (Well Logger) Journal, 3-4, pp. 155-165. (In Russian).

Gogonenkov, G.N., A.S. Kashik, A.I. Timurziev 2007: Basement strike-sip faults in West Siberia. Geologiya nefti i gaza (Oil and Gas Geology) Journal, 3, pp. 3-11. (In Russian).

Gogonenkov, G.N., A.S. Lavrik, S.S. Elmanovich 2002: Incipient strike-slip faults in tectonics of northern West Siberia. - Geofizika (Geophysics) Journal, Special issue on seismic technology, pp. 54-62. (In Russian).

Hoeppener, R.E., H.N. Karthoff, P. Schrader 1969: Zur physikalischen Tectonik, Bruchbildung bei verschiedenen Deformation im Experiment. - Geol. Rundsch. 59, pp. 179-193.

Jaroszewski, W. 1974: Tektonika uskokow i faldow. - Wydawnictwa Geologiczne, Warsawa, p. 360.

Khanty-Mansi Autonomous Area Geology and Presence of Oil and Gas Atlas 2004: V. I. Shpilman Scientific-Analytic Center for Rational Subsurface Wealth Use, Khanty-Mansiysk town, 149 p. (In Russian).

Kontorovich, A.E., I.I. Nesterov 2000: Structure map for West Siberian syneclise along top Aptian-Cenomanian. - Novosibirsk City. (In Russian).

Naylor, M.A., G. Mandl, C.H.K. Sijpesteijn 1986: Fault geometries in basement-induced wrench faulting under different initial stress states. - Journal of Structural Geology, 8/7, pp. 737-752.

Skorobogatov, V.A., L.V. Stroganov, V.D. Kopeyev 2003: Yamal Peninsula geology and oil-and-gas presence. - Moscow, Nedra Publishers, 350 p. (In Russian).

Surkov, V.V., O.G. Zhero 1981: The basement and West Siberian plate sedimentary cover development, Moscow, Nedra Publishers, 143 p. (In Russian).

Sylvester, A.G. 1988, Strike-slip faults. - Geol. Soc. Amer. Bull., 100, pp. 1666-1703.

Vyssotski, A.V., V.N. Vyssotski, A.A. Nezhdanov. 2006: Evolution of the West Siberian Basin. - Marine and Petroleum Geology, 23, pp. 93-126. 